\title{
Uncertainty quantification through bayesian analysis for a fixed bed experiment of carbon capture using polyethylenimine (PEI) solid sorbents
}

Brian T. Logsdon

Follow this and additional works at: https://researchrepository.wvu.edu/etd

\section{Recommended Citation}

Logsdon, Brian T., "Uncertainty quantification through bayesian analysis for a fixed bed experiment of carbon capture using polyethylenimine (PEI) solid sorbents" (2016). Graduate Theses, Dissertations, and Problem Reports. 6107.

https://researchrepository.wvu.edu/etd/6107

This Thesis is protected by copyright and/or related rights. It has been brought to you by the The Research Repository @ WVU with permission from the rights-holder(s). You are free to use this Thesis in any way that is permitted by the copyright and related rights legislation that applies to your use. For other uses you must obtain permission from the rights-holder(s) directly, unless additional rights are indicated by a Creative Commons license in the record and/ or on the work itself. This Thesis has been accepted for inclusion in WVU Graduate Theses, Dissertations, and Problem Reports collection by an authorized administrator of The Research Repository @ WVU. For more information, please contact researchrepository@mail.wvu.edu. 


\title{
UNCERTAINTY QUANTIFICATION THROUGH BAYESIAN ANALYSIS FOR A FIXED BED EXPERIMENT OF CARBON CAPTURE USING POLYETHYLENIMINE (PEI) SOLID SORBENTS
}

\author{
Brian T. Logsdon
}

\author{
Thesis submitted to the \\ Benjamin M. Statler College of Engineering and Mineral Resources \\ at West Virginia University \\ in partial fullfillment of the requirements for the degree of \\ Master of Science \\ in \\ Mechanical Engineering
}

David S. Mebane, Chair Ph.D.

Kenneth Means, Ph.D.

Debangsu Bhattacharyya, Ph.D.

Department of Mechanical and Aerospace Engineering

Morgantown, West Viriginia

2016

Keywords: Uncertainty Quantification, Carbon Capture, Fixed Bed Reactor, Amine Sorbents

Copyright (C) 2016 


\begin{abstract}
Uncertainty Quantification Through Bayesian Analysis for a Fixed Bed Experiment of Carbon Capture Using Polyethylenimine (PEI) Solid Sorbents

Brian Logsdon
\end{abstract}

With greenhouse gas emissions becoming a major concern and topic for research over the past decade, much effort has been supplied into the progress of reducing these emissions. Carbon dioxide concentration has increased over past 60 years. A major source of this emission is post combustion coal power plants. In order to reduce these emissions, many carbon capture and storage technologies are being researched and developed. A major issue confronting this research is investigating these technologies on multiple scales. For example, solid sorbents experience phenomena on a quantum and macroscopic scale. Thus a bridge must be made between these two scales.

This thesis investigates a fixed bed experiment, proposes a model for both the flow and adsorption of $\mathrm{CO}_{2} \& \mathrm{H}_{2} \mathrm{O}$, and then quantifies the uncertainty of parameter estimations made with comparing the model to data. The model and uncertainty quantification was implemented in a $\mathrm{C}++$ tool set. The power of this tool set lies in the ability to extract more information out of bench scale experiments than traditional optimization methods. This leads to better predictions in modeling a larger (process) scale, better understanding of the mathematical model used at the bench scale, and information to design better bench scale experiments to reduce the uncertainty.

The results of this analysis with the proposed model showed the posterior predictions covering the real data set. In other words, the posterior distribution includes a set of parameters that are the "true" values. Information on the certainty of each parameter estimation was also obtained in this analysis. 


\section{Contents}

1 Introduction $\quad 1$

1.1 Objective \& Contributions . . . . . . . . . . . . . . . . . 1

1.2 Thesis Structure . . . . . . . . . . . . . . . . . 2

2 Background $\quad 3$

2.1 Global Climate Change . . . . . . . . . . . . . . . . . . 3

2.2 Carbon Dioxide Gas Accumulation . . . . . . . . . . . . . . . 4

2.3 Carbon Capture \& Storage . . . . . . . . . . . . . . . . 5

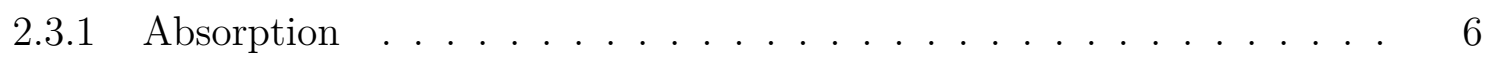

2.3.2 Membrane Separation ................... 8

2.3.3 Cryogenic Separation . . . . . . . . . . . . . . . . 9

2.3.4 Adsorption .......................... 10

2.3.5 Multi-Scale Modeling . . . . . . . . . . . . . . . 14

2.3.6 Bayesian Techniques . . . . . . . . . . . . . . 15

3 TGA Experiment Analysis $\quad 16$

3.1 First Generation Model . . . . . . . . . . . . . . . . . . . . 17

3.2 TGA Experiment Modeling Results . . . . . . . . . . . . . . . . . . 19

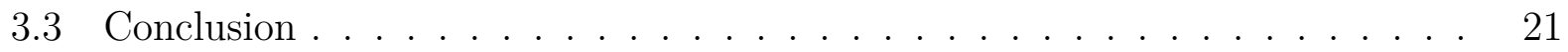

4 Fixed Bed Model Development $\quad 22$ 
4.1 Fixed Bed Reactor Experiment . . . . . . . . . . . . . . . . . 22

4.2 First Generation 2.0 Model . . . . . . . . . . . . . . . . . . . . . . 23

4.3 Fixed Bed Gas Flow Model . . . . . . . . . . . . . . . . . 25

4.4 Numerical Discretization and Solution _ . . . . . . . . . . . . 27

5 Parameter Estimation Methodology 30

5.1 Particle Swarm Optimizer . . . . . . . . . . . . . . . . . . . 31

5.2 Uncertainty Quantification Methodology . . . . . . . . . . . . . . . 32

6 Results and Discussion $\quad 36$

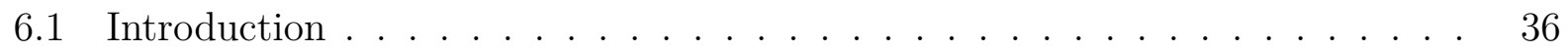

6.2 Data Generation . . . . . . . . . . . . . . . . 36

6.3 Fixed Bed Posterior . . . . . . . . . . . . . . . . . . . . . . . . . 39

$6.3 .1 \quad$ Parameter Priors . . . . . . . . . . . . . . . . . . . . . . . . 39

6.3 .2 Reality Coverage . . . . . . . . . . . . . . . . . 39

6.3 .3 Parameter Analysis . . . . . . . . . . . . . . . . . . . . 44

7 Conclusions \& Accomplishments $\quad 50$ 


\section{List of Figures}

$2.1 \mathrm{CO}_{2}$ trend over past four years $[40] \ldots \ldots \ldots \ldots \ldots$

$2.2 \mathrm{CO}_{2}$ capture technologies strawman $[18] \ldots \ldots \ldots$

2.3 Proposed reaction chemistry for chemical absorption in amine solvents [17] . 7

2.4 Schematic of membrane separation $[13] \ldots \ldots \ldots \ldots$

2.5 Process diagram of cryogenic separation $[44] \ldots \ldots \ldots$

2.6 Comparison of volumetric $\mathrm{CO} 2$ capacity for MOFs, zeolite 13X pellets and MAXSORB carbon powder $[37] \ldots \ldots \ldots \ldots \ldots$

2.7 Typical silica xerogel agglomerates of mesoporous particles $[22] \ldots \ldots 12$

2.8 Polyethylenimine $[8] \ldots \ldots \ldots \ldots \ldots$

2.9 Multiple scales of problem . . . . . . . . . . . . . . . . . 14

3.1 Q600 SDT thermo gravimetric analyzer from TA Instruments $[21] \ldots \ldots$

3.2 NETL-32D TGA trace . . . . . . . . . . . . . . . . . . . . 17

3.3 Uncertainty quantification of TGA experiment $\left(\Delta H_{c}, \Delta S_{c}, \Delta H_{c}^{\ddagger}\right) \ldots \ldots 20$

4.1 Image of mini $\mathrm{C} 2 \mathrm{U}$ fixed bed reactor $\ldots \ldots \ldots 23$

4.2 Finite volume illustration . . . . . . . . . . . . . . . . . . . . . 28

4.3 Sketch of Crank-Nicholson scheme . . . . . . . . . . . . . . . . 28

5.1 Illustration of burn in . . . . . . . . . . . . . . . . . . . . 35

6.1 Generated experimental data sets . . . . . . . . . . . . . . . . 38

6.2 Posterior model pressure drop predictions . . . . . . . . . . . . . . . . 40 
6.3 Posterior model $\mathrm{CO}_{2} \%$ outlet predictions $\ldots \ldots \ldots$. . . . . . . . 40

6.4 Posterior model $\mathrm{CO}_{2} \%$ outlet predictions zoomed in . . . . . . . . . . 41

6.5 Posterior model $\mathrm{H}_{2} \mathrm{O} \%$ outlet predictions . . . . . . . . . . . . . 42

6.6 Posterior model $\mathrm{H}_{2} \mathrm{O} \%$ outlet predictions zoomed in . . . . . . . . . . . 42

6.7 Posterior distributions for carbamate formation $\ldots \ldots \ldots . \ldots 44$

6.8 Posterior distributions for water adsorption . . . . . . . . . . . . . 45

6.9 Posterior distributions for bicarbonate formation . . . . . . . . . . . 46

6.10 Posterior distributions for site densities . . . . . . . . . . . . . 47

6.11 Posterior distributions for the mobility parameter f . . . . . . . . . . 48 


\section{List of Tables}

3.1 First generation model variable descriptions . . . . . . . . . . . . . . . . . 19

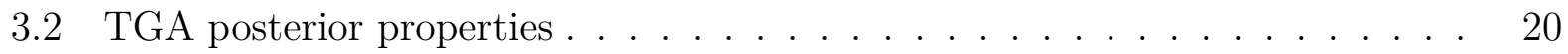

4.1 First generation 2.0 model variable descriptions . . . . . . . . . . . . . 25

4.2 Model field variables . . . . . . . . . . . . . . . . . . . . . . 27

5.1 Model parameters . . . . . . . . . . . . . . . . . . . . . . . . . . 31

6.1 Parameters for data set . . . . . . . . . . . . . . . . . . . . 37

6.2 Parameter priors . . . . . . . . . . . . . . . . . . . . . . . 39

6.3 Real values for equilibrium and rate constants of data . . . . . . . . . . 49

6.4 Fixed bed posterior properties . . . . . . . . . . . . . . . . 49

6.5 Fixed bed posterior convergence confidence . . . . . . . . . . . . . . 49 


\section{Chapter 1}

\section{Introduction}

Currently a major subject of research is focused on power \& energy systems. Much of this work involves investigating and using mathematical models to obtain information about ma-

terial properties and their respective behavior when exposed to different conditions. However, these materials must be used at an industrial scale. The extrapolation of these results from smaller scale to the larger scale is not a straight forward process because the error is also extrapolated. Thus more intelligent methods must be used, i.e. uncertainty quantification through Bayesian analysis.

\section{$1.1 \quad$ Objective \& Contributions}

The ultimate goal \& objective of this work is to provide a tool set capable of providing single point estimates, as well as uncertainty quantification, for reaction enthalpies, entropies, activation enthalpies, pre-exponential factors, and site densities for amine solid sorbents used in carbon capture \& storage systems. As it stands now, technologies for this application face a major time and expense challenge when dealing with the connection of modeling in this multi-scale problem. This work will add to the CCSI tool set allowing for fixed bed reactor data to be analyzed to learn more about amine sorbents. 


\subsection{Thesis Structure}

The structure of this thesis starts with the background and motivation. Overviews of global climate change, greenhouse gases, carbon capture technologies, and multi-scale modeling will be discussed. This will then lead into a discussion of thermo gravimetric data, its analysis, and motivation for fixed bed reactor experiments. The next section contains the full description and derivation of the mathematical model for the fixed bed reactor experiment, along with the analysis methodology. Lastly the results and conclusion of this analysis and tool set will be discussed. 


\section{Chapter 2}

\section{Background}

\subsection{Global Climate Change}

Global climate change due to greenhouse gases has been a major topic of concern and research over the past couple decades. Greenhouse gases include methane, carbon monoxide, nitrous oxide, chlorofluorocarbon, and primarily carbon dioxide. According to the United States Environmental Protection Agency (EPA), in 2013, $\mathrm{CO}_{2}$ gas accounted for $82 \%$ of all U.S. greenhouse gas emissions from human activities. [1] There are many ways $\mathrm{CO}_{2}$ can be emitted into the atmosphere. Sources of these emissions include agriculture, industrial processes, transportation, and primarily production of electricity. The EPA reports, in 2013, that $31 \%$ of all greenhouse gas emissions are caused by the burning of fossil fuels to produce electricity. [1] These fossil fuels include coal, oil, and natural gas.

The main question surrounding this is what do these emissions result in? The final outcome of greenhouse gas accumulation is not known. What is known is that scientific evidence exists proving greenhouse gases are a factor in earth heating up. This, on a general level, occurs during the interaction between the sun and earth. The sun radiates energy to earth that is either absorbed or reflected back to space. Non-greenhouse gases do not interfere with this process. However, greenhouse gases absorb some of the energy being 
reflected back to space. That energy or heat is then trapped within in earth's atmosphere. The trapped heat then leads to an overall temperature increase in earth's climate. For this reason, these effects are of deep concern, to ensure the planet's stability.

\subsection{Carbon Dioxide Gas Accumulation}

$\mathrm{CO}_{2}$ gas accumulating in the atmosphere is obviously a concern due to the effect described above. Due to current emissions the concentration of carbon dioxide in the atmosphere is on the rise. Below is a figure of the carbon dioxide concentration in the atmosphere for the past four years supplied by the National Oceanic \& Atmospheric Administration (NOAA).

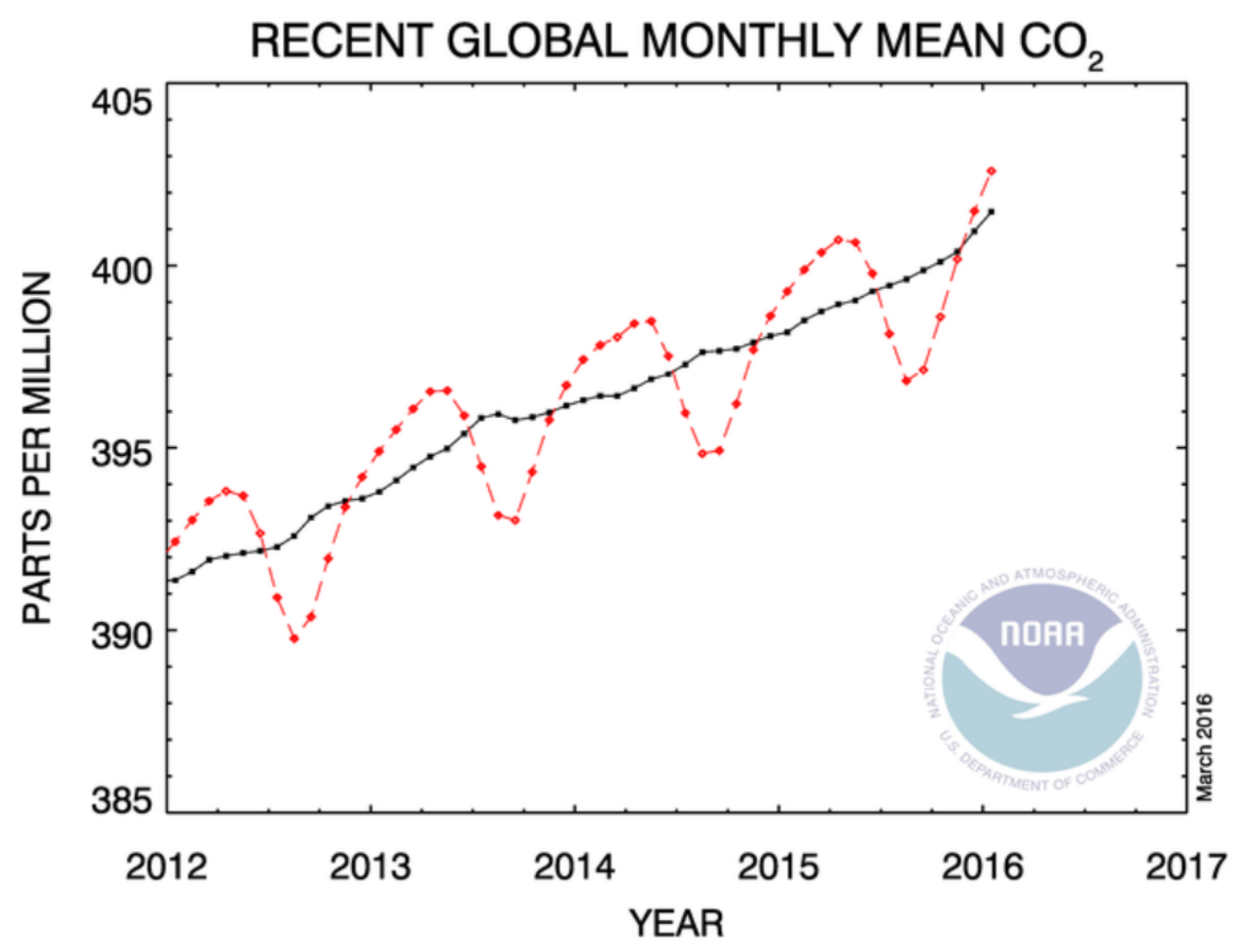

Figure 2.1: $\mathrm{CO}_{2}$ trend over past four years [40] 
As shown above the concentration of $\mathrm{CO}_{2}$ is on the increase globally. The EPA reports that in 1950 the concentration was just above 300 ppm (parts per million). [1] It is clear to see that over the past 65 years $\mathrm{CO}_{2}$ concentration in the atmosphere keeps escalating and will continue unless adjustments are implemented. As it stands, non-fossil fuel energy alternatives such as nuclear, biomass, solar energy, etc cannot fulfill the every growing energy demand of today. This is due to the level of cost and risk involved with these sources. [18] Until theses sources become more cost effective and risk is reduced, other measures need to be taken. To combat the build up of carbon dioxide in the atmosphere, carbon capture \& storage (CCS) systems are being researched and developed.

\subsection{Carbon Capture \& Storage}

One group pursing this is the Carbon Capture Simulation Initiative (CCSI) Project. The CCSI project began in February of 2011 and is Department of Energy (DOE) funded. This project is a partnership among national laboratories, industry, and academic institutions that is developing, demonstrating, and deploying state-of-the-art computational modeling and simulation tools to accelerate the commercialization of carbon capture technologies from discovery to pilot scale, demonstration, and ultimately widespread deployment to hundreds of power plants. [36] With power plants being a crucial point of impact for greenhouse gas, many technologies have been researched with the mission of reducing these emissions. Technologies for this include amine scrubbing, membrane separation and cryogenic separation. [18] Figure(2.2) presents a strawman of the different technologies used in CCS. 


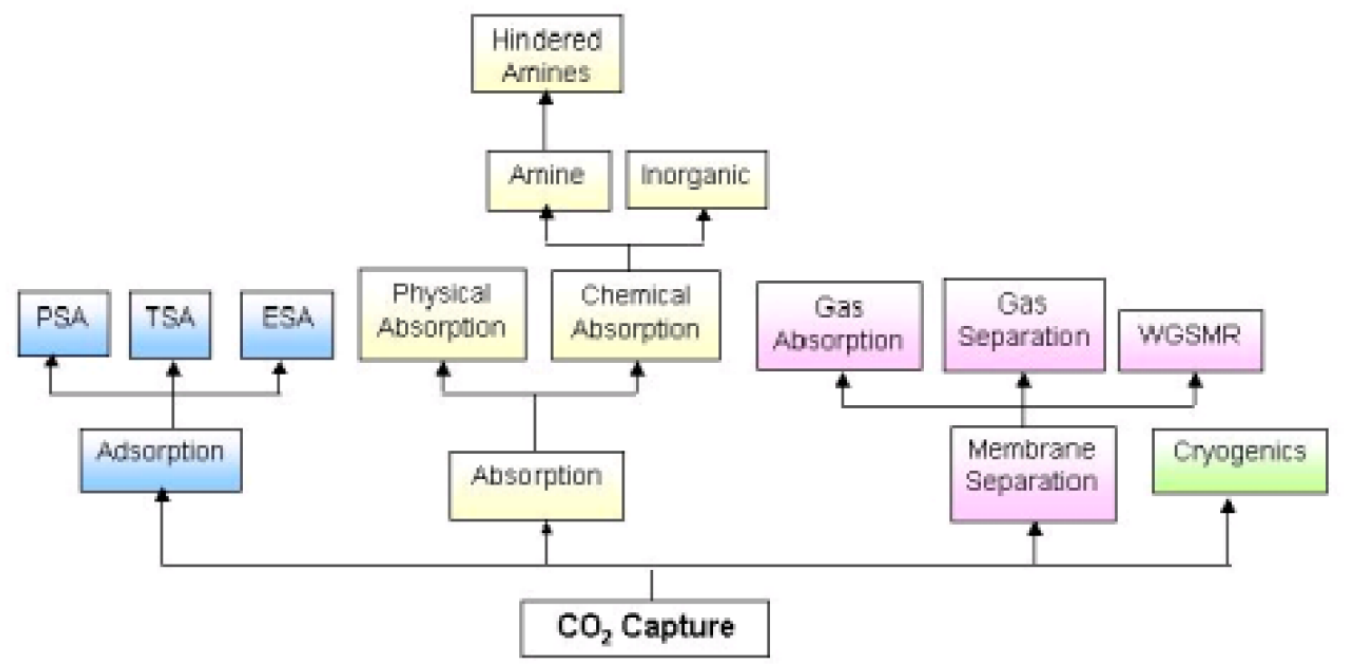

Figure 2.2: $\mathrm{CO}_{2}$ capture technologies strawman [18]

Next a discussion of the categories in Figure (2.2) will be discussed based on their current progress, advantages, and disadvantages.

\subsubsection{Absorption}

Chemical absorption technologies consist of a gas or fluid being dissolved by another fluid. In carbon dioxide capture, the absorbent is either a alkaline, ionic-liquid based, or blended aqueous solvent which neutralizes $\mathrm{CO}_{2}$ gas. [51] When the $\mathrm{CO}_{2}$ gas comes in contact with the solvent, the gas is absorbed from the gas phase into the liquid phase. This takes place in what is called the absorber. Now having the $\mathrm{CO}_{2}$ trapped, the solvent can be heated which breaks the solvent down into a concentrated flow of carbon dioxide. This process is completed in the stripper. The concentrated stream of $\mathrm{CO}_{2}$ is then compressed for transportation and storage. The left-over solvent can then be recycled back into the absorber for capture again. The operating pressure for this method of CCS is usually around 1.0 bar. The absorber operates around $40^{\circ} \mathrm{C}$ to $60^{\circ} \mathrm{C}$, while the striper generally operates around $120^{\circ} \mathrm{C}$ to $140^{\circ} \mathrm{C}$. [51] The proposed chemistry for absorption in amine solvents is presented in Figure (2.3). 


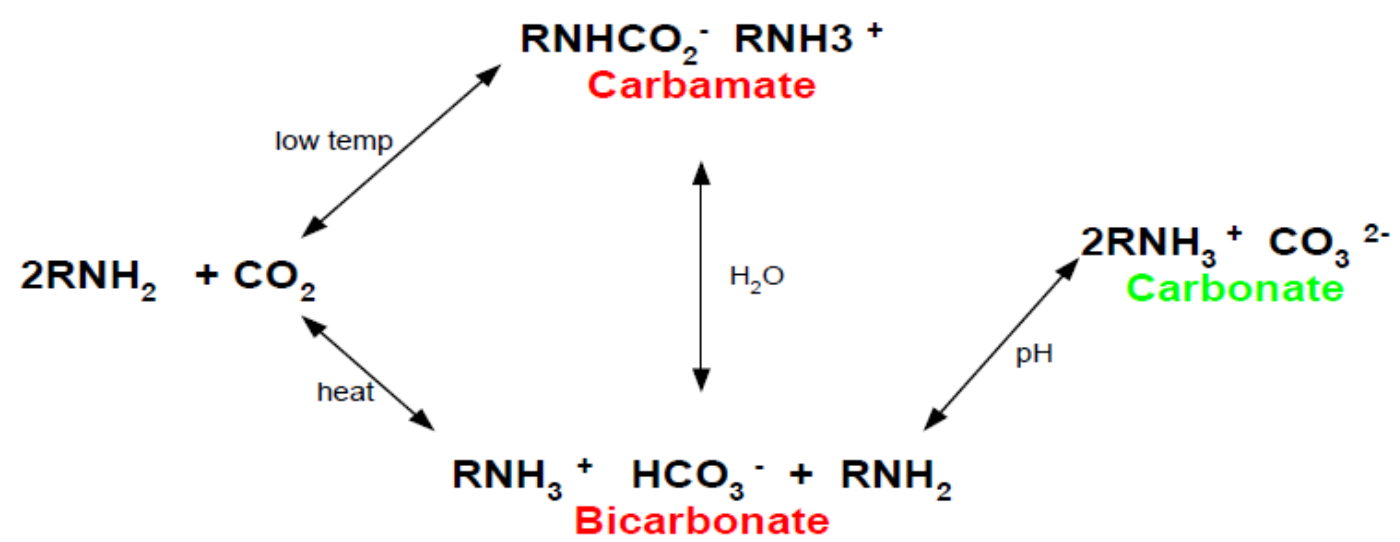

Figure 2.3: Proposed reaction chemistry for chemical absorption in amine solvents [17]

Figure (2.3) proposes the absorption mechanism using primary and secondary alkanolamines in liquid based amine solvents. [17]. As shown in the figure, the majority of carbon dioxide that has been dissolved in the solvent will form bicarbonate. For this to be stable, two amines per mole of $\mathrm{CO}_{2}$ is required in the aqueous media. [17]

This technology has many advantages, with the first being its maturity. Chemical absorption has been commercialized for many decades, but not for $\mathrm{CO}_{2}$ capture. Another advantage is that the technology can be added to existing power plants. [51] This will lower cost when designs for adding CCS technologies to power plants are implemented. Lastly, the transportation and handling of these absorbents are much easier than a solid adsorbent.

This technology also faces disadvantages as well. These solvents have a low $\mathrm{CO}_{2}$ loading capacity. [51] This is a major disadvantage for cost purposes. With a low carbon dioxide loading, more solvent is necessary, which adds to the price of the solvent, as well as the cost of transportation and handling. Equipment corrosion and amine degradation are also major concerns with this technology. Lastly the regeneration process require a large amount of energy. 


\subsubsection{Membrane Separation}

Another technology for carbon capture that has been investigated is membrane separation. The primary idea behind membrane separation is that the membrane is used to selectively separate the gas of concern $\left(\mathrm{CO}_{2}\right)$ from a mixture of gases. This technology has already been commercialized for the removal or carbon dioxide from natural gas. [35] Silica, inorganic, polymeric [45, 42], carbon, alumina, facilitated transport membranes [42], and more have been investigated for this application. The two characteristics of a membrane that control the separation are the permeability and selectivity to the gas of interest. These parameters of the membrane are affected by the material properties of the gas, velocity of the flow, and membrane material properties. Figure(2.4) represents a schematic for plate membrane separation.

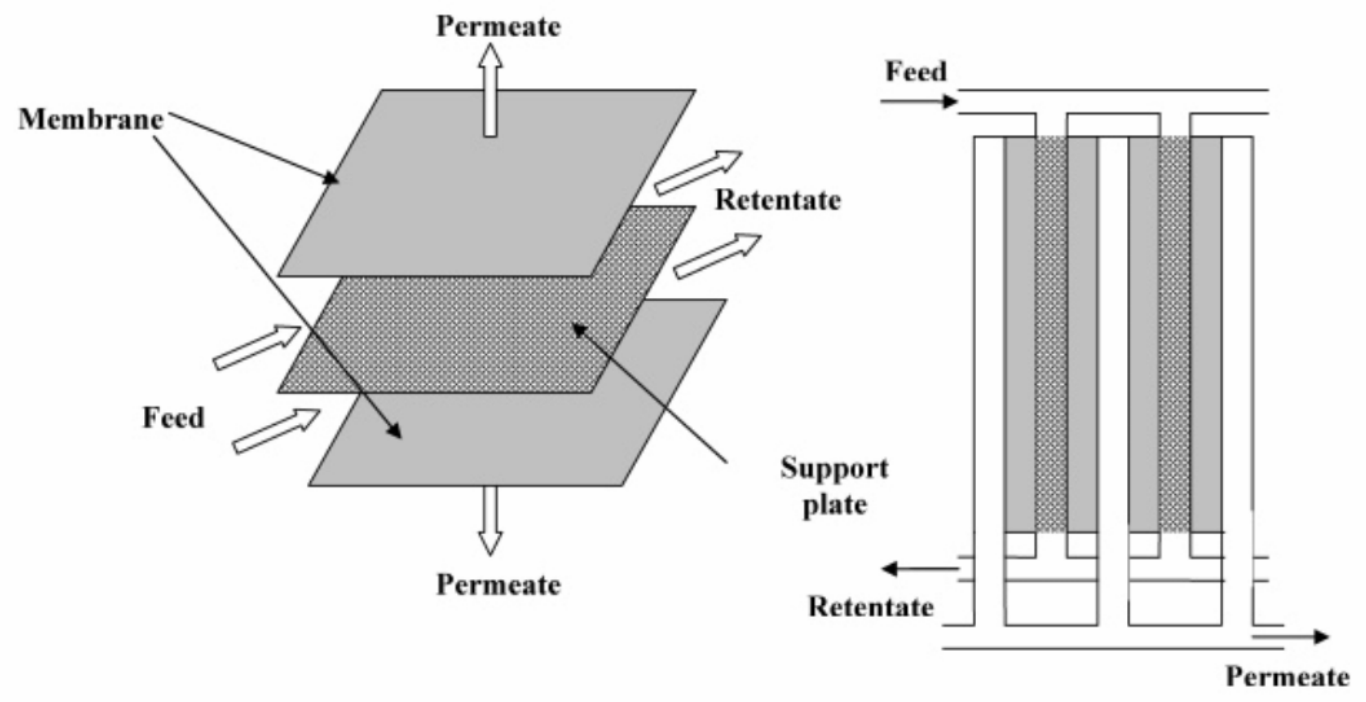

Figure 2.4: Schematic of membrane separation [13]

The first advantage of this technology deals with the energy cost associated with it. Heat is not needed for regeneration like the previously discussed absorbents. Another advantage is the simplicity of construction of this technology. No moving parts and the ability to be 
quite compact allow for relatively easy control and operation. [42] However, this technology is plagued by crucial disadvantages. The operating temperature of these membranes must not exceed $100^{\circ} \mathrm{C}$ if the membrane is organic, or the membrane will deteriorate quickly. This requires the cooling of the flue gas, which adds complexity and cost. Also, impurities in the flue gas extremely affect the performance of the membranes. Lastly, membranes are do not have a high enough selectivity or permeability for $\mathrm{CO}_{2}$. This results in low capture rates and makes this technology ineffective for CCS applications. [38]

\subsubsection{Cryogenic Separation}

Cryogenic separation is another method for carbon capture. This technology involves the separation of $\mathrm{CO}_{2}$ using condensation. A major requirement of this technology is that any impurities must be removed from the flue gas before using this process. If this is completed, the conditions can be set in which $\mathrm{CO}_{2}$ condense, while $\mathrm{N}_{2}$ remains in the gas phase. One method of this process was proposed by Tunier's group. The process consists of using a packed bed set up, in which the $\mathrm{CO}_{2}$ is de-sublimated into the packing material. Then it is released to produce pure $\mathrm{CO}_{2}$ gas. [47]. Another method was proposed by Clodic's group involving the use of heat exchanger fins. $\mathrm{CO}_{2}$ is de-sublimated onto the surface of the fins, and then it is recovered as liquid carbon dioxide at high pressures. Figure (2.5) is a process diagram of this proposal. [9] 


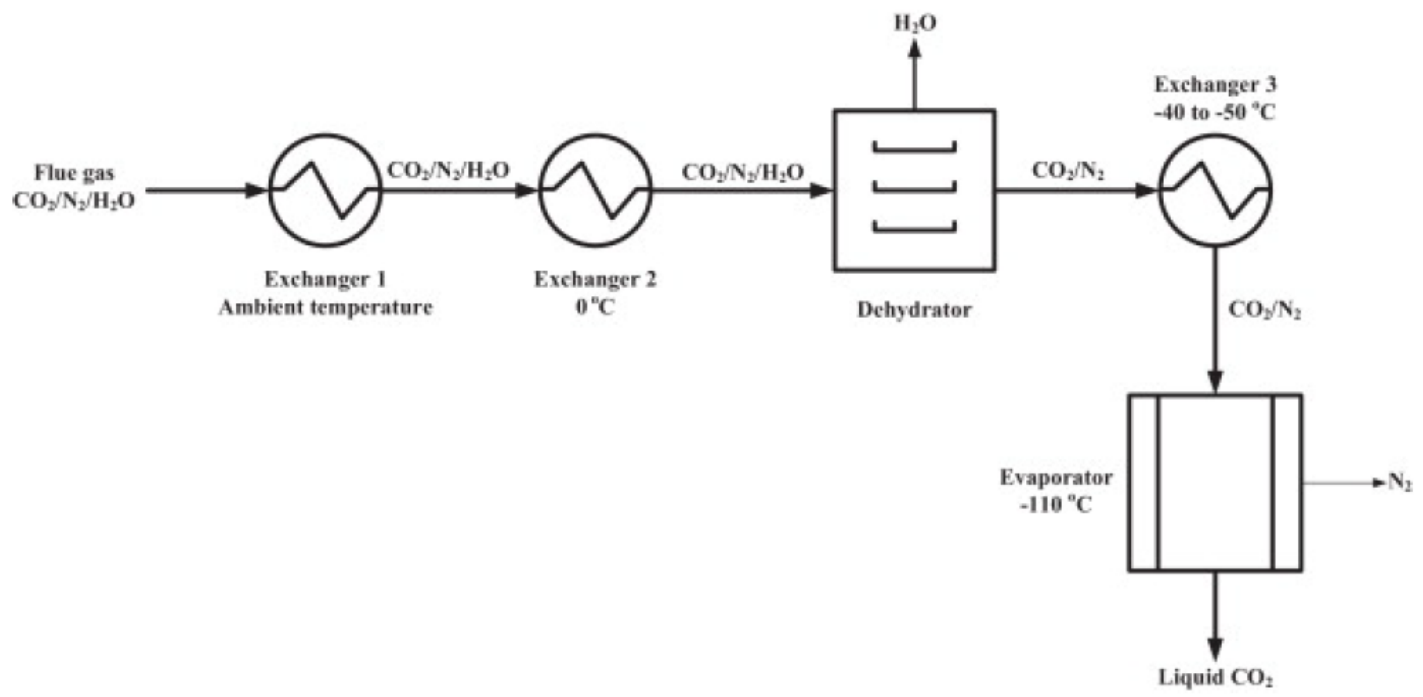

Figure 2.5: Process diagram of cryogenic separation [44]

\subsubsection{Adsorption}

One promising technology for $\mathrm{CO}_{2}$ gas capture is adsorption. Adsorption differs from absorption because adsorption deals with the intermolecular forces between the gas and sorbent. Instead of $\mathrm{CO}_{2}$ gas dissolving into a solvent and then binding to the amines, the gas is adsorbed on the surface of the sorbent. The mechanism for adsorption can be broken down into two types, physisorption and chemisorption.

\section{Physisorption}

Physisorption is the process of the gas forming a physical bond with the sorbent. This is a much weaker bond than chemisorption, however can be used for $\mathrm{CO}_{2}$ separation applications. Materials for this process are porous solid adsorbents. Characteristics such as pore size, distribution, structure, and active surface structure are the key factors in adsorption efficiency. Materials for this application include but are not limited to activated carbons [11], ordered mesoporous silica [30, 10, 6], zeolites, and metal-organic frameworks 
(MOFs) $[27,50,39,48,4,3,5,25,28]$. A comparison of $\mathrm{CO}_{2}$ loading between these materials is shown in Figure (2.6).

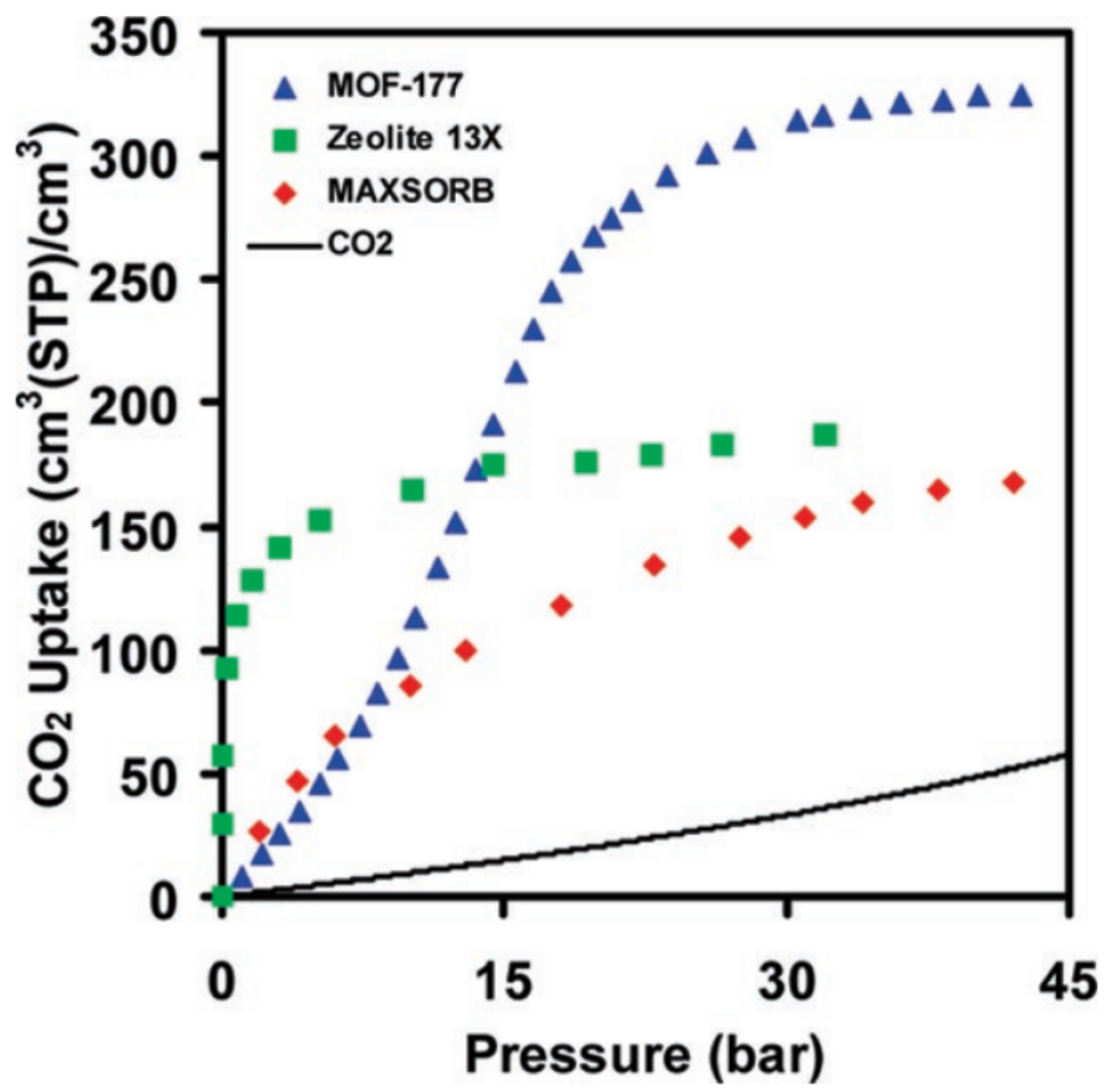

Figure 2.6: Comparison of volumetric CO2 capacity for MOFs, zeolite 13X pellets and MAXSORB carbon powder [37]

Advantages of this technology consist of low cost, high thermal stability, and ease or regeneration. Disadvantages include a negative affect of temperature on adsorption capacity. Also this technology has low $\mathrm{CO}_{2}$ selectivity, which is a major drawback. 


\section{Chemisorption}

Chemisorption is the process of gas molecules coming into contact with the surface of the sorbent and forming a chemical bond. This is a much stronger bond than the previously discussed physical bond. In 1992, silica supported amines were first introduced for the process of $\mathrm{CO}_{2}$ capture. [46] There are two types, ordered porosity and disordered porosity. An example of disordered porosity can be seen silica xerogel. These structures are hard to characterize, which make them difficult to understand. Figure(2.7) is a high resolution image of these silica xerogel agglomerates of mesoporous particles. [22].

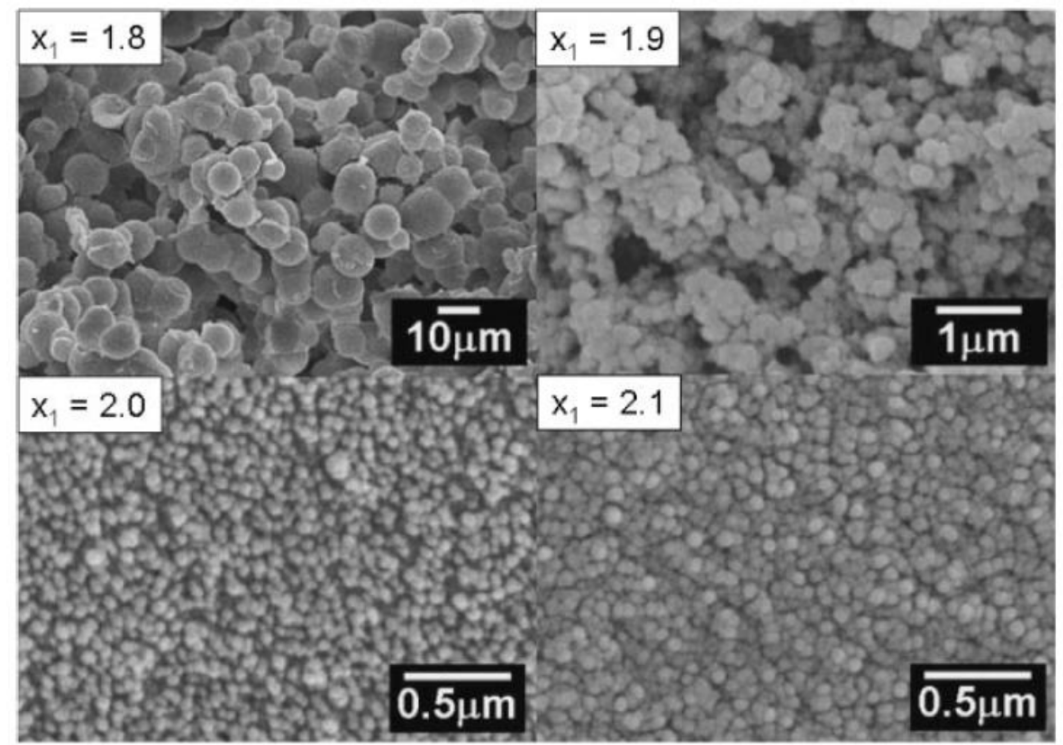

Figure 2.7: Typical silica xerogel agglomerates of mesoporous particles [22]

Ordered porosity structures have many advantages for scientific investigation. They are relatively easily created, easy to characterize, and aspects of the structure can be designed or tuned. The structure can be created in two ways. The amines can be covalently bounded to the substrate through the reaction of an aminosilane with silanol groups on the silica surface. $[17,26,19,20,53,29]$ Another synthesis process physically impregnates the amine 
into the silica. $[34,49,15,52,43,12,14,31,41]$ Much research has been investigated into amine impregnated silica, such as MCM-41, SBA-15, SBA-16, and more for $\mathrm{CO}_{2}$ capture.

A commonly used amine for this technology is polyethylenimine (PEI) which consists of linear or branched primary, secondary, and tertiary amines. Figure(2.8) shows the structure of PEI.

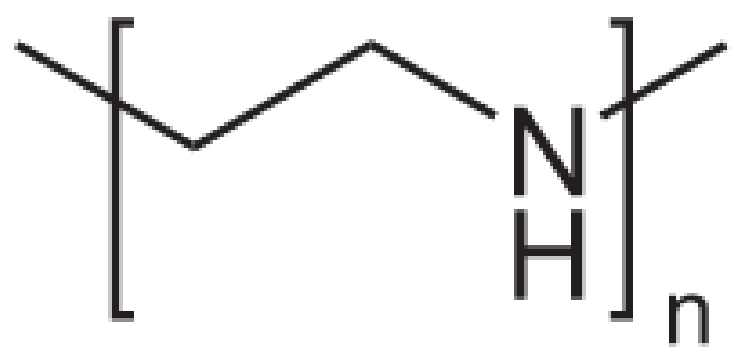

Figure 2.8: Polyethylenimine [8]

This technology has multiple advantages when used for this application. The first advantage is that these amine sorbents possess almost a complete chemical selectivity to $\mathrm{CO}_{2}$ over $\mathrm{N}_{2}$ gas. Another advantage is the solid amines can be utilized at high operating temperatures $\left(\mathrm{T}>100^{\circ} \mathrm{C}\right)$, as apposed to absorption technologies. Lastly, the $\mathrm{CO}_{2}$ loading is greatly increased in the presence of water. Flue gas already contains water vapor, which encourages this effect in power plants.

Solid sorbents were selected to be the demonstration case for the CCSI tool set. The amine selected for this demonstration was Polyethylenimine (PEI), which was impregnated into the mesoporous silica. The National Energy Technology Laboratory (NETL) produced a series of sorbents, with the best performing sorbent being named "NETL-32D". The supports of this structure are macroporous agglomerates of the mesoporous silica particle, and the PEI is impregnated into these mesopores where bonds to the substrate. 


\subsubsection{Multi-Scale Modeling}

The challenge many technologies in development face, including solid sorbents, is that they experience phenomena on a quantum scale as well a macroscopic scale [32].
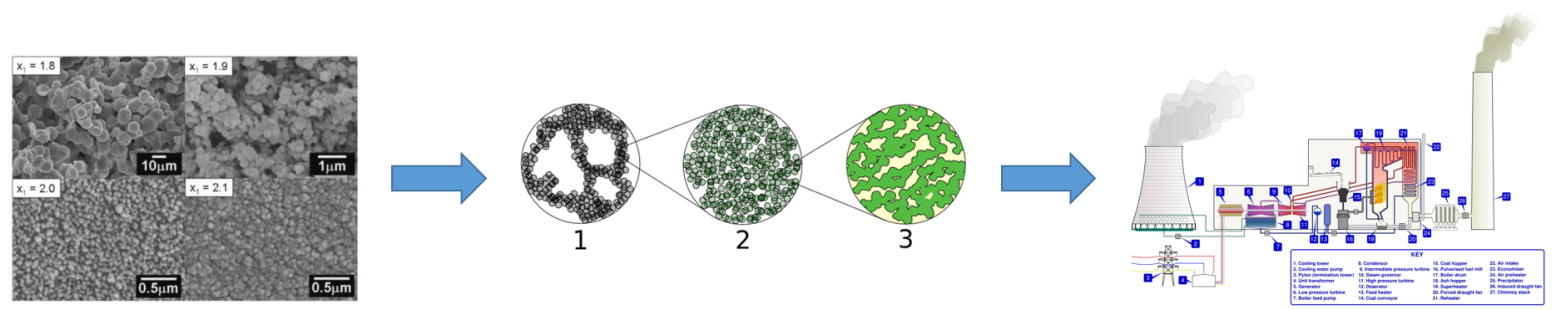

Figure 2.9: Multiple scales of problem

Facing this challenge, it is essential for the phenomena must be explored on all scales. In order to achieve this, models and experiments must be done at all scales, starting with the bench scale. Understanding how the sorbent behaves on a quantum scale will allow for a more accurate prediction of how the technology will behave when implemented at an industrial scale. This is important because process scale experiments are very costly and time consuming, so having better predictions will save time and money. Experiments for this tool set demonstration at the bench scale for these technologies include thermo gravimetric analysis and fixed bed reactor experiments. Experiments at this level can provide information for estimates about the parameters at the quantum scale. These parameters include, but are not limited to, reaction enthalpies, entropies, activation enthalpies, and number of adsorption sites. These estimations can then be propagated into larger scale models leading to process scale models. By using this process, all aspects of the phenomena are captured and models can better predict on a process scale. Then using the predictions from the process scale models, better technologies and bench scale experiments can be designed. This iterative process continues until the most optimal design for a carbon capture system has been established. 


\subsubsection{Bayesian Techniques}

Bayesian frameworks have been used for many applications in engineering. The CCSI group has already demonstrated the application of quantifying the uncertainty through Bayesian analysis. [36] Matthew Realff's group from Georgia Institute of Technology has also been investigating and demonstrating the use of Bayesian techniques in research. They have proposed a new method for the design of experiments (DOE) using Bayesian analysis to obtain as much information from the experiment as possible. Using Bayesian techniques they created a new decision oriented DOE strategy. This strategy demonstrated a significant improval for the prediction of a process's optimal objective function over the traditional approach. [2] 


\section{Chapter 3}

\section{TGA Experiment Analysis}

Thermo gravimetric analysis (TGA) has proven to be an effective bench-scale experiment to learn about many adsorption and desorption mechanisms of many materials, as well as

other process phenomenon. The procedure for this is that a small sample is placed in a quartz microbalance, and then the sorbent is purged by exposing it to inert gas, such as nitrogen, at high temperatures. Next reactive gases are pumped into the chamber, causing adsorption to happen, which is measured by the microbalance. The experimentalist can then adjust the temperature and concentration of the reactive gas to observe how the material, or in this case sorbent, behaves. [33]. Figure (3.1) shows a sample TGA apparatus from TA Instruments. [21]

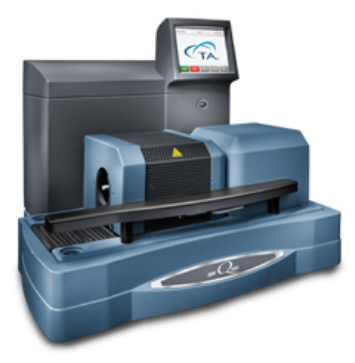

Figure 3.1: Q600 SDT thermo gravimetric analyzer from TA Instruments [21] 
For the CCSI tool set demonstration, NETL-32D was analyzed. A $50 \mathrm{mg}$ sample was placed in the microbalance and analyzed as it was exposed to a multi component flow of $\mathrm{CO}_{2}, \mathrm{H}_{2} \mathrm{O}$, and $\mathrm{N}_{2}$. The concentrations were kept constant per simulation with temperature varying. Also, the overall chamber pressure was maintained at atmospheric conditions. Figure (3.2) shows a sample TGA trace of NETL-3D exposed to $\mathrm{CO}_{2}$ and $\mathrm{H}_{2} \mathrm{O}$.

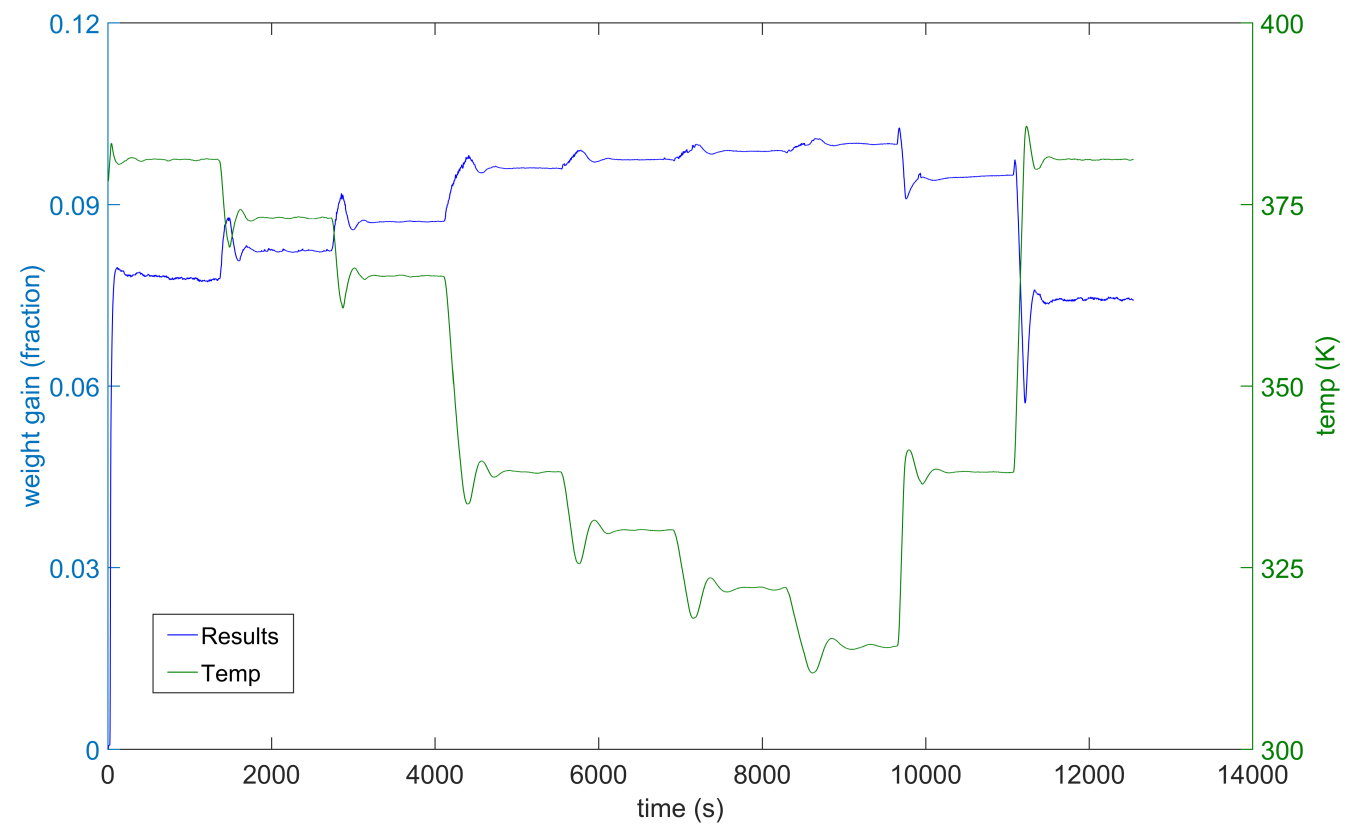

Figure 3.2: NETL-32D TGA trace

\subsection{First Generation Model}

In order to model this experiment, a chemical reaction system was made to describe the adsorption and desorption of $\mathrm{CO}_{2}$ and $\mathrm{H}_{2} \mathrm{O}$ in the sorbent. This reaction system was named the first generation model. It is comprised of three reactions. The first reaction describes $\mathrm{CO}_{2}$ gas chemisorbing into the sorbent at two free amine sites to form alkylammonium carbamate. The second reaction represents $\mathrm{H}_{2} \mathrm{O}$ in the gas phase physisorbing into the sorbent. The last 
reaction describes the formation of bicarbonate from $\mathrm{CO}_{2}$ gas, adsorbed $\mathrm{H}_{2} \mathrm{O}$, and one free amine site. Below are the chemical reactions for the First Generation Model:

$$
\begin{aligned}
& \mathrm{CO}_{2}(\text { gas })+2 \mathrm{R}_{2} \mathrm{NH} \rightleftarrows \mathrm{R}_{2} \mathrm{NH}_{2}^{+}: \mathrm{R}_{2} \mathrm{NCOO}^{-} \\
& \mathrm{H}_{2} \mathrm{O}(\text { gas }) \rightleftarrows \mathrm{H}_{2} \mathrm{O}(\text { phys }) \\
& \mathrm{CO}_{2}(\text { gas })+\mathrm{H}_{2} \mathrm{O}(\text { phys })+\mathrm{R}_{2} \mathrm{NH} \rightleftarrows \mathrm{R}_{2} \mathrm{NH}_{2}^{+}: \mathrm{HCO}_{3}^{-}
\end{aligned}
$$

Using these three reactions, mass action rate expression can be formulated. Below are these expressions, along with a table of variable descriptions.

$$
\begin{gathered}
\frac{\partial x}{\partial t}=k_{c}\left[s^{2} p_{c}-\frac{x w}{\kappa_{c}}\right] \\
\frac{\partial a}{\partial t}=k_{h}\left[p_{h}-\frac{a}{\kappa_{h}}\right]-k_{b}\left[\operatorname{sap}_{c}-\frac{b w}{\kappa_{b}}\right] \\
\frac{\partial b}{\partial t}=k_{b}\left[s a p_{c}-\frac{b w}{\kappa_{b}}\right]
\end{gathered}
$$

where:

$$
\begin{gathered}
s=1-x-w \\
w=x+\frac{b}{n_{v}} \\
k_{*}=\zeta_{*} T \exp \left(\frac{-\Delta H_{*}^{\ddagger}}{R T}\right) \\
\kappa_{*}=\exp \left(\frac{\Delta S_{*}}{R}\right) \exp \left(\frac{-\Delta H_{*}}{R T}\right) / P
\end{gathered}
$$


Table 3.1: First generation model variable descriptions

\begin{tabular}{||c|c||}
\hline Variable & Description \\
\hline$x$ & Site fraction of carbamate formation \\
\hline$a$ & Concentration of water adsorption \\
\hline$b$ & Concentration of bicarbonate formation \\
\hline$s$ & Site fraction of free amine \\
\hline$w$ & Protonated amine site fraction \\
\hline$p_{c}$ & Partial pressure of $\mathrm{CO}_{2}$ \\
\hline$p_{h}$ & Partial pressure of $\mathrm{H}_{2} \mathrm{O}$ \\
\hline$\kappa_{*}$ & Equilibrium constant of reaction "** \\
\hline$k_{*}$ & Rate constant of reaction "* \\
\hline$P$ & Atmospheric pressure at sea level \\
\hline
\end{tabular}

\subsection{TGA Experiment Modeling Results}

This first generation model for $\mathrm{CO}_{2}$ and $\mathrm{H}_{2} \mathrm{O}$ adsorption has been implemented to analyze TGA experimental data. This analysis was done in two ways. First the model was empirically fitted to the data using a particle swarm optimizer technique. Next uncertainty quantification was conducted by starting the Markov Chain Monte Carlo routine at the optimal solution. Uncertainty quantification is a process in which Bayesian statistics are used to generated a posterior probability distribution of the model parameters given the TGA data. Below is the posterior distribution of the reaction enthalpy and entropy, and activation energy of carbamate formation with the corresponding bivariate joint posterior distributions. While all 13 model parameters were analyzed, only three are shown to illustrate the motivation for fixed bed analysis. 

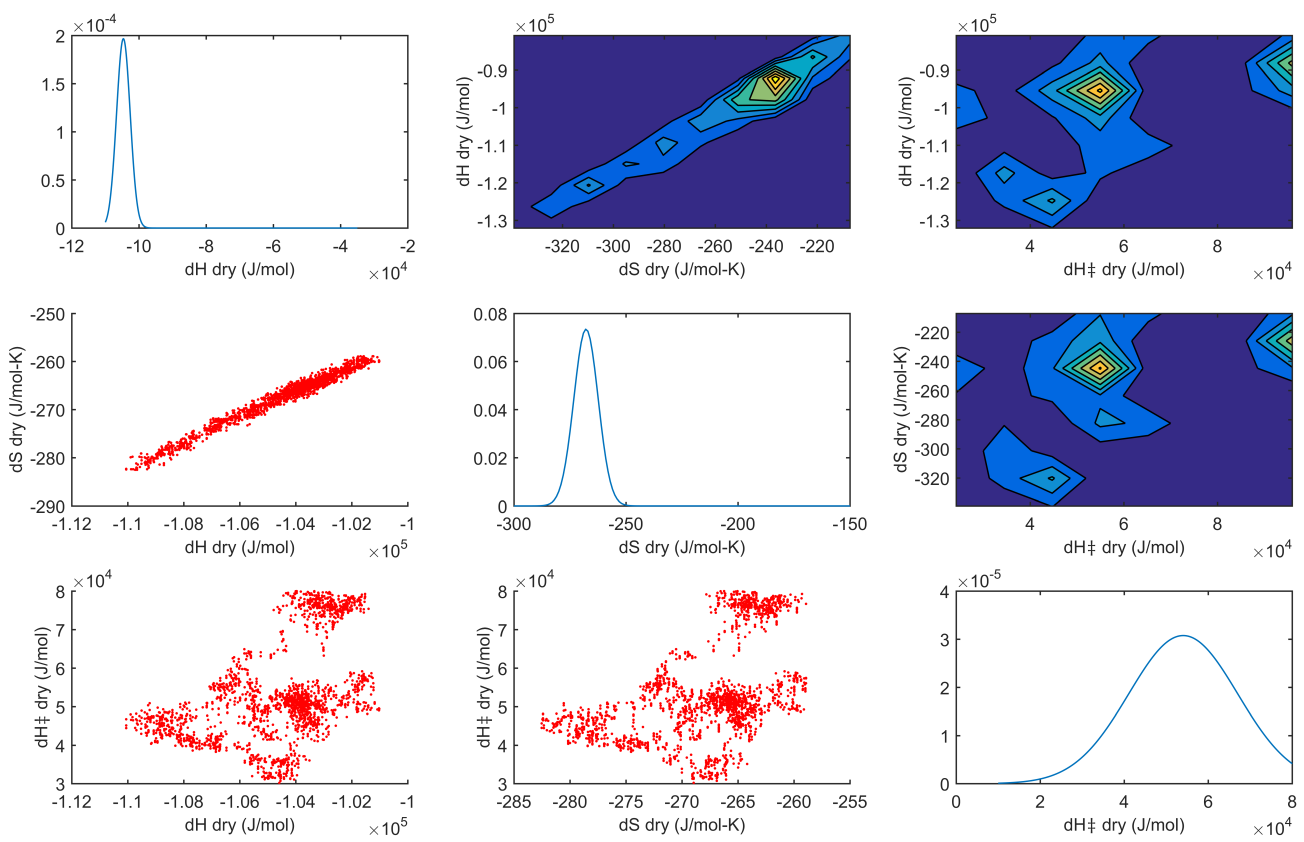

Figure 3.3: Uncertainty quantification of TGA experiment $\left(\Delta H_{c}, \Delta S_{c}, \Delta H_{c}^{\ddagger}\right)$

Table (3.2) shows the standard deviation $(\sigma)$ and mean $(\mu)$ of each parameter's posterior.

Table 3.2: TGA posterior properties

\begin{tabular}{|c|c|c|c|c|c|}
\hline Parameter & $\sigma$ & $\mu$ & Parameter & $\sigma$ & $\mu$ \\
\hline$\Delta H_{c}\left(\frac{J}{m o l}\right)$ & $2.1697 \times 10^{3}$ & $-1.1750 \times 10^{5}$ & $\Delta H_{h}^{\ddagger}\left(\frac{J}{m o l}\right)$ & $6.3327 \times 10^{3}$ & $5.5423 \times 10^{4}$ \\
\hline$\Delta S_{c}\left(\frac{J}{m o l-K}\right)$ & 5.7545 & -301.74 & $\zeta_{h}$ & 1.0282 & 3.4632 \\
\hline$\Delta H_{c}^{\ddagger}\left(\frac{J}{m o l}\right)$ & $1.9529 \times 10^{4}$ & $4.0829 \times 10^{4}$ & $\Delta H_{b}\left(\frac{J}{m o l}\right)$ & $1.2263 \times 10^{4}$ & $-1.2250 \times 10^{5}$ \\
\hline$\zeta_{c}$ & 1.8592 & 1.9161 & $\Delta S_{b}\left(\frac{J}{m o l-K}\right)$ & 41.0688 & -164.11 \\
\hline$n_{v}\left(\frac{m o l}{m^{3}}\right)$ & 22.6835 & $1.8724 \times 10^{3}$ & $\Delta H_{b}^{\ddagger}\left(\frac{J}{m o l}\right)$ & $1.2676 \times 10^{4}$ & $1.0156 \times 10^{5}$ \\
\hline$\Delta H_{h}\left(\frac{J}{m o l}\right)$ & 773.42 & $-6.6781 \times 10^{4}$ & $\zeta_{b}$ & 2.2832 & -1.3935 \\
\hline$\Delta S_{h}\left(\frac{J}{m o l-K}\right)$ & 2.4036 & -123.42 & & & \\
\hline
\end{tabular}




\subsection{Conclusion}

The results of this analysis yielded that the TGA experiment provided a significant amount of information for the equilibrium parameters. This was represented by the fact that there is a tight narrow posterior distribution for the reaction enthalpy and entropy. However, it was discovered to have little information about the kinetic parameters of the model as shown above in Figure (3.3). This is represented by the activation enthalpy for carbamate formation having a very broad posterior distribution. 


\section{Chapter 4}

\section{Fixed Bed Model Development}

The conclusion of the conducted thermo gravimetric analysis provided the motivation to investigate a different bench scale experiment that could provide more kinetic information about these reactions. The chosen bench scale experiment to investigate and model was the Fixed Bed Reactor experiment. The fixed bed reactor experiment is a commonly used experiment in the study of chemical processes. The goal was to calculate better estimates for the kinetic parameters of carbon capture process.

\subsection{Fixed Bed Reactor Experiment}

There are many setups for fixed bed systems. The one chosen for this demonstration was the mini $\mathrm{C} 2 \mathrm{U}$ housed at NETL in Morgantown, WV. The design consisted of a four inch diameter pipe, with gas flow being driven vertically through the bed. $\mathrm{CO}_{2}$ analyzers and a mass spectrometer were placed at the outlet. 


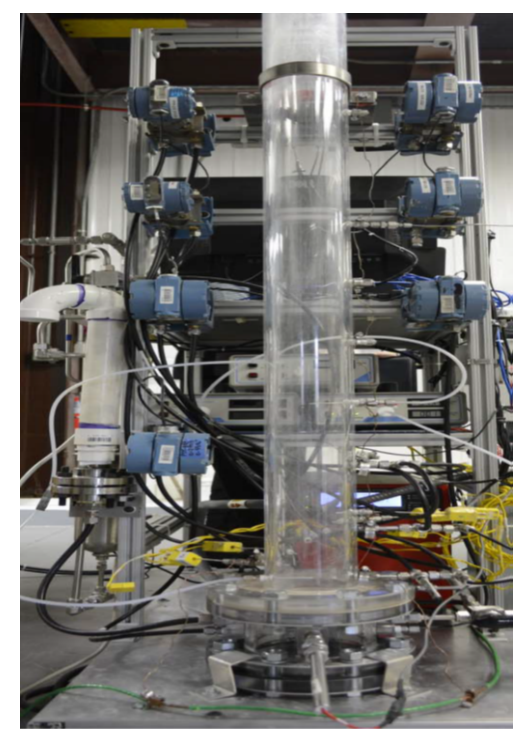

Figure 4.1: Image of mini $\mathrm{C} 2 \mathrm{U}$ fixed bed reactor

When attempting to model this experiment, issues arose with modeling the adsorption of water. Using the First Generation Model to govern this reaction proved to be unrealistic due to the fact there is no site limitation. In order to remedy this situation, a new set of chemical reactions were formulated. This led to the First Generation 2.0 Model.

\subsection{First Generation 2.0 Model}

The First Generation 2.0 Model is very similar to the original model, however this model accounts for the fact that water is site limited. The actual sites for this physisorption are unknown and are represented as water adsorption sites. Three reactions occur, just as before. First, $\mathrm{CO}_{2}$ gas chemisorbs onto two free amine site to form carbamate. Next $\mathrm{H}_{2} \mathrm{O}$ gas physisorbs into the sorbent at a free water adsorption site. Lastly, a physisorbed $\mathrm{H}_{2} \mathrm{O}$ molecule and $\mathrm{CO}_{2}$ gas react to form bicarbonate. This model assumes that the kinetics of each reaction are dominated by a single, ideally behaved chemical reaction. 


$$
\begin{aligned}
& \mathrm{CO}_{2}(\text { gas })+2 \mathrm{R}_{2} \mathrm{NH} \rightleftarrows \mathrm{R}_{2} \mathrm{NH}_{2}^{+}: \mathrm{R}_{2} \mathrm{NCOO}^{-} \\
& \mathrm{H}_{2} \mathrm{O}(\text { gas })+\mathrm{S}_{\mathrm{h}} \rightleftarrows \mathrm{H}_{2} \mathrm{O}(\text { phys }) \\
& \mathrm{CO}_{2}(\text { gas })+\mathrm{H}_{2} \mathrm{O}(\text { phys })+\mathrm{R}_{2} \mathrm{NH} \rightleftarrows \mathrm{R}_{2} \mathrm{NH}_{2}^{+}: \mathrm{HCO}_{3}^{-}+\mathrm{S}_{\mathrm{h}}
\end{aligned}
$$

In order to simulate the adsorption of $\mathrm{CO}_{2}$ and $\mathrm{H}_{2} \mathrm{O}$, three mass-action rate expressions can be derived. Below are the three rate expressions for the reactions mention above, along with a table of variable descriptions.

$$
\begin{gathered}
\frac{\partial x}{\partial t}=k_{c}\left[s^{2} p_{c}-\frac{x^{2}}{\kappa_{c}}\right] \\
\frac{\partial a}{\partial t}=k_{h}\left[p_{h}(1-a)-\frac{a}{\kappa_{h}}\right]-k_{b}\left[\operatorname{sap}_{c}-\frac{b(1-a)}{\kappa_{b}}\right] \\
\frac{\partial b}{\partial t}=k_{b}\left[\operatorname{sap}_{c}-\frac{b(1-a)}{\kappa_{b}}\right]
\end{gathered}
$$

where:

$$
\begin{gathered}
s=1-2 x-b \\
k_{*}=\zeta_{*} T \exp \left(\frac{-\Delta H_{*}^{\ddagger}}{R T}\right) \\
\kappa_{*}=\exp \left(\frac{\Delta S_{*}}{R}\right) \exp \left(\frac{-\Delta H_{*}}{R T}\right) / P
\end{gathered}
$$


Table 4.1: First generation 2.0 model variable descriptions

\begin{tabular}{|c|c||}
\hline Variable & Description \\
\hline$x$ & Site fraction of carbamate formation \\
\hline$a$ & Site fraction of water adsorption \\
\hline$b$ & Site fraction of bicarbonate formation \\
\hline$s$ & Site fraction of free amine \\
\hline$p_{c}$ & Partial pressure of $\mathrm{CO}_{2}$ \\
\hline$p_{h}$ & Partial pressure of $\mathrm{H}_{2} \mathrm{O}$ \\
\hline$\kappa_{*}$ & Equilibrium constant of reaction "*» \\
\hline$k_{*}$ & Rate constant of reaction "*" \\
\hline$P$ & Atmospheric pressure at sea level \\
\hline
\end{tabular}

\subsection{Fixed Bed Gas Flow Model}

Now that the chemical model has been established, it must be combined with a flow model to simulate the full fixed bed experiment. To create this flow model, Darcy's Law in 1-dimension was used to govern the flow of gas through a porous media. Below is the representation of this law, with $Q$ representing the flux of gas, $A$ being the cross sectional area of the bed, $\frac{\partial P}{\partial x}$ denoting the driving force of pressure drop, and $M$ is the mobility of gas through the porous structure. The mobility parameter is an empirical constant that takes into account the system's physical properties such as the structure of media, viscosity of the gas, etc.

$$
Q=-M A \frac{\partial P}{\partial x}
$$

This expression needs to be modified as there are multiple gases flowing through the bed $\left(\mathrm{CO}_{2}, \mathrm{H}_{2} \mathrm{O}, \mathrm{N}_{2}\right)$ to reflect the flow of just one particular gas. The following expression governs the flow of gas $_{i}$ through a control volume. Where $n_{i}$ is the number of moles of gas 
and $n$ is the total number of moles of gas in the control volume.

$$
Q_{i}=-M A\left(\frac{n_{i}}{n}\right) \frac{\partial P}{\partial x}
$$

Using Equation (4.5) to governs the flux of a single species in a multi-component flow, two conservation of mass expressions can be written. The first equation represents the conservation of $\mathrm{CO}_{2}$ molecules.

$$
\frac{\partial n_{c}}{\partial t}=-M A\left(\frac{n_{c}}{n}\right) \nabla^{2} P-r_{c}
$$

In equation (4.6) $r_{c}$ is the sink rate of $\mathrm{CO}_{2}$ gas in the flow due to adsorption. This can be calculated from the rate expressions for carbamate and bicarbonate by simply multiplying them by the number of active amines sites per volume $\left(n_{v}\right)$ and the volume of the sorbent $\left(V_{s}\right)$ in the control volume.

$$
r_{c}=n_{v} V_{s}\left(\frac{\partial x}{\partial t}+\frac{\partial b}{\partial t}\right)
$$

The second equation is the conservation of $\mathrm{H}_{2} \mathrm{O}$ molecules.

$$
\frac{\partial n_{h}}{\partial t}=-M A\left(\frac{n_{h}}{n}\right) \nabla^{2} P-r_{h}
$$

Equation (4.8) $r_{h}$ represents the sink rate of $\mathrm{H}_{2} \mathrm{O}$ gas in the flow due to adsorption. This is very similar to the expression for $r_{c}$, except instead of multiplying by $n_{v}$, the rate of water adsorption must be multiplied by $n_{h}$ (number of water adsorption sites). Below is this expression.

$$
r_{h}=n_{h} V_{s}\left(k_{h}\left[p_{h}(1-a)-\frac{a}{\kappa_{h}}\right]\right)
$$

Lastly the assumption of incompressible flow was made. This provided a conservation of mass expression for the entire flow through the bed, equation (4.10). 


$$
0=-M A \nabla^{2} P-r_{c}-r_{h}
$$

Now that the six nonlinear ODE's have been formulated for each control volume (Equations (4.1),(4.2),(4.3),(4.6),(4.8),(4.10)), a discretization and solution method must be formulated.

\subsection{Numerical Discretization and Solution}

Now that the governing equations have been established, a methodology for solving this system of equations must be created. There are six equations with a total of six field variables per control volume.

Table 4.2: Model field variables

\begin{tabular}{||c|c||}
\hline Variable & Description \\
\hline$x$ & Site fraction of carbamate formation \\
\hline$a$ & Site fraction of water adsorption \\
\hline$b$ & Site fraction of bicarbonate formation \\
\hline$n_{c}$ & Number of $\mathrm{CO}_{2}$ moles in gas \\
\hline$n_{h}$ & Number of $\mathrm{H}_{2} \mathrm{O}$ moles in gas \\
\hline$P$ & Total pressure of gas \\
\hline
\end{tabular}

For the three equations dealing with gas flow, a finite volume scheme was implemented. This provided for a solution in the length domain of the problem. Figure (4.2) is an illustration of this method. 

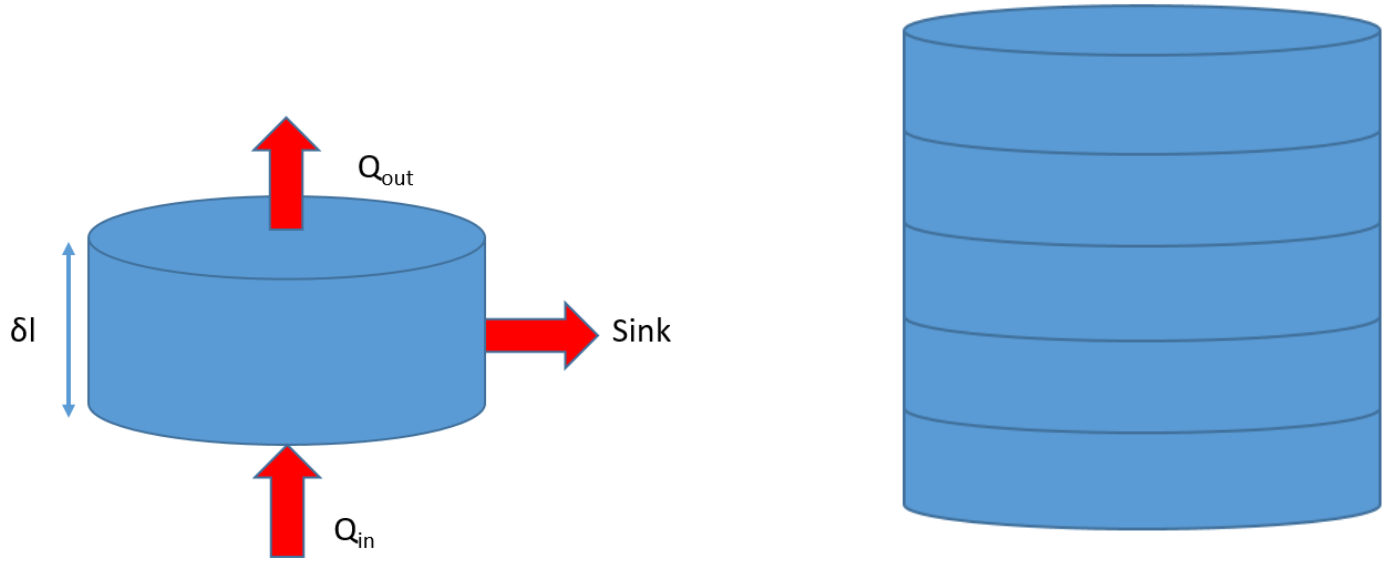

Figure 4.2: Finite volume illustration

Not only does space need to be discretized, but time does as well. The discretization chosen for time was a Crank-Nicholson scheme. Crank-Nicholson is 2nd order accurate and has proven to be quite stable for many applications. Equation (4.11) represents the CrankNicholson scheme and Figure (4.3) shows the discretization in space and time.

$$
\frac{u_{j}^{n+1}-u_{j}^{n}}{k}=\frac{1}{2}\left(\frac{u_{j+1}^{n+1}-2 u_{j}^{n+1}+u_{j-1}^{n+1}}{h}+\frac{u_{j+1}^{n}-2 u_{j}^{n}+u_{j-1}^{n}}{h}\right)
$$

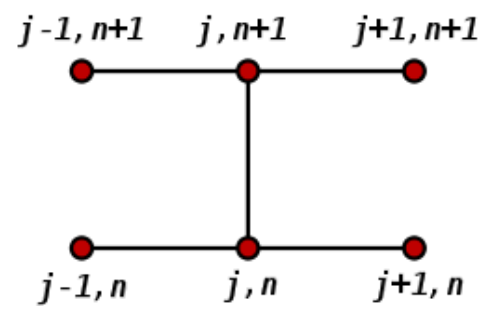

Figure 4.3: Sketch of Crank-Nicholson scheme

Using the above methods for discretization, a system of nonlinear equations was created. To solve this system, Newton's Method was employed. Newton's method starts with initial guess and calculates a search direction. Below shows the matrix expression for finding the next guess, which requires the Jacobian and function to be evaluated at the initial guess. 


$$
\left[\begin{array}{c}
x_{1}^{k+1} \\
x_{2}^{k+1} \\
\ldots \\
x_{n}^{k+1}
\end{array}\right]=\left[\begin{array}{c}
x_{1}^{k} \\
x_{2}^{k} \\
\ldots \\
x_{n}^{k}
\end{array}\right]+\left[\begin{array}{ccc}
\frac{\partial f_{1}\left(x^{k}\right)}{\partial x_{1}} & \ldots & \frac{\partial f_{1}\left(x^{k}\right)}{\partial x_{n}} \\
\ldots & & \ldots \\
\ldots & & \ldots \\
\frac{\partial f_{n}\left(x^{k}\right)}{\partial x_{1}} & \ldots & \frac{\partial f_{n}\left(x^{k}\right)}{\partial x_{n}}
\end{array}\right]^{-1}\left[\begin{array}{c}
f_{1}\left(x^{k}\right) \\
f_{2}\left(x^{k}\right) \\
\ldots \\
f_{n}\left(x^{k}\right)
\end{array}\right]
$$

The Jacobian for this problem was found to be a non-symmetric matrix. Due to the nature of this matrix, a generalized minimal residual method (GMRES) was used to solve for the search direction. This was supplied by the EIGEN C++ Library. Once the search direction was found, Armijo's rule was applied. This allowed the residual tolerance to increase by a small amount to help get the model out of a rough spot in the solution space. Once convergence was met, the time step advanced and the model was solved again. 


\section{Chapter 5}

\section{Parameter Estimation Methodology}

Now that a mathematic model for this experiment has been created and coded, analysis using genetic algorithms can be performed. These genetic algorithms are used to estimate the parameters associated with the model discussed earlier. The 15 model parameters are listed and detailed in Table (5.1). 
Table 5.1: Model parameters

\begin{tabular}{||c|c||}
\hline Parameter & Description \\
\hline$\Delta H_{c}$ & Reaction enthalpy of carbamate formation $(\mathrm{J} / \mathrm{mol})$ \\
\hline$\Delta S_{c}$ & Reaction entropy of carbamate formation $(\mathrm{J} / \mathrm{mol}-\mathrm{K})$ \\
\hline$\Delta H_{c}^{\ddagger}$ & Activation enthalpy of carbamate formation $(\mathrm{J} / \mathrm{mol})$ \\
\hline$\zeta_{c}$ & Pre-exponential factor of carbamate formation \\
\hline$n_{v}$ & Total number of active amine sites $\left(\mathrm{mol} / \mathrm{m}^{3}\right)$ \\
\hline$\Delta H_{h}$ & Reaction enthalpy of water physisorbtion $(\mathrm{J} / \mathrm{mol})$ \\
\hline$\Delta S_{h}$ & Reaction entropy of water physisorbtion $(\mathrm{J} / \mathrm{mol}-\mathrm{K})$ \\
\hline$\Delta H_{h}^{\ddagger}$ & Activation enthalpy of water physisorbtion $(\mathrm{J} / \mathrm{mol})$ \\
\hline$\zeta_{h}$ & Pre-exponential factor of water physisorbtion \\
\hline$n_{h}$ & Total number of water absorption sites $\left(\mathrm{mol} / \mathrm{m}{ }^{3}\right)$ \\
\hline$\Delta H_{b}$ & Reaction enthalpy of bicarbonate formation $(\mathrm{J} / \mathrm{mol})$ \\
\hline$\Delta S_{b}$ & Reaction entropy of bicarbonate formation $(\mathrm{J} / \mathrm{mol}-\mathrm{K})$ \\
\hline$\Delta H_{b}^{\ddagger}$ & Activation enthalpy of bicarbonate formation $(\mathrm{J} / \mathrm{mol})$ \\
\hline$\zeta_{b}$ & Pre-exponential factor of bicarbonate formation \\
\hline$M_{1}$ & Porous media parameter \\
\hline
\end{tabular}

In this tool set, two types of genetic algorithms are available. First is a particle swarm optimizer, which provides the best fixed point estimate. The other is uncertainty quantification through Bayesian analysis, which provides an qualitative sense of the uncertainty of these estimates and describes the information available in the data set.

\subsection{Particle Swarm Optimizer}

The first genetic algorithm applied to this model was a particle swarm optimizer (PSO). This method searches the parameter space and "swarms" to the most optimal parameter set [23]. 
This method has proved to be a efficient method to find a fixed point estimate for the model parameters. At initialization, "agents"(individual with a set of parameters) are randomly spread out across the parameter space. Once initialized, each agent's fitness to the data is evaluated. Given that each agent evaluation is independent from the other, parallelization can be taken advantage of. Thus using cluster computing techniques, a significant number of agents can be added to the search without sacrificing speed. Once all agents are evaluated, they move towards their best neighbor agent, however the agent will, on a random basis, move in the wrong direction. This "randomness" is implemented in the routine on purpose. The purpose of this method is to enhance exploration of the parameter space by forcing agents to not always take the direct route to the optimum. This reduces the chance of converging on a local optimum.

While this analysis of a model provides a quick estimate for the desired parameters, it is just a fixed point estimate. There is no guarantee that the complete parameter space was searched. Also, there is no level of uncertainty associated with this estimation. The major effect of this is felt when the results are scaled to a process model because the error propagates with it. This drawback provided the motivation for developing a technique of quantifying the uncertainty of these parameter estimations.

\subsection{Uncertainty Quantification Methodology}

Statistics can be primarily broken down into two categories, frequentest \& Bayesian. Frequentest is generally what most people reference when discussing statistics. However Bayesian statistics is a completely different perspective, and using a Bayesian framework can be more informative in parameter estimation. This framework treats the data as fixed and the model parameters as random variables. Bayes Theorem provides the calculation of the probability of obtaining the model parameters $(\theta)$, when observing data $(Y)$. 


$$
P(\theta \mid Y)=\frac{P(Y \mid \theta) P(\theta)}{\int_{\theta^{\prime}} P\left(Y \mid \theta^{\prime}\right) P\left(\theta^{\prime}\right) d \theta^{\prime}}
$$

$\mathrm{P}(\theta \mid Y)$ is the posterior distribution of the parameters. $\mathrm{P}(\theta)$ is the prior distribution of the model parameters. $\mathrm{P}(Y \mid \theta)$ is named the likelihood, which is probability of observing the data $(Y)$ given model parameters $(\theta)$. The denominator is simply the probability of observing data $(Y)$ integrated over all possibilities of model parameters $\theta$. Bayes Theorem is the framework in which the uncertainty quantification process is built from, with the goal of providing an estimation (posterior distribution) of unknown parameters $(\theta)$, by comparing the model results given $\theta$ with the data $(Y)$.

The statistical model presented by Kennedy \& O'Hagan, excluding discrepancy terms, leads to the posterior distribution being comprised of two parts (likelihood \& observational error). [24] Equation (5.2) expresses this statistical model with $M(\theta)$ being the model results given parameters $\theta$ and observational error given input $\psi$.

$$
Y=M(\theta)+\epsilon(\psi)
$$

Now applying Bayes theorem, the posterior distribution is formulated:

$$
\Omega(\theta, \psi \mid Y) \propto \mathcal{L}(Y \mid \theta, \psi) \pi(\theta, \psi)
$$

$\pi(\theta, \psi)$ denotes the priors for both model parameters and the observational error. For the model parameters, a bounded uniform distribution was used. These prior distributions must be bounded because these parameters have physical limitations. The prior used for $\psi$ was an inverse gamma distribution that enabled the use of Gibbs sampling. $\mathcal{L}(Y \mid \theta, \psi)$ represents the likelihood. The calculation of the likelihood considers four variables. The first two are the inputs of model parameters $(\theta)$ with model inputs $M$ and observational error $(\psi)$. The other two are the realistic data $Y$ and the number of data sample points $n$. Thus: 


$$
\mathcal{L}(\theta, \psi)=(2 \pi)^{-n / 2}(\psi)^{-n / 2} \exp \left\{\frac{-1}{2 \psi}\left[(Y-M(\theta))^{\prime}(Y-M(\theta))\right]\right\}
$$

Now having these terms formulated, a Markov Chain Monte Carlo (MCMC) [7, 16] routine can be constructed. The MCMC starts with initial point in the parameter space. This starting point is either chosen by a guess or one can use the results of the PSO. An initial likelihood and $\psi$ are calculated from this spot in the parameter space. This is the start of the Markov chain. From here, parameters are proposed one at a time by drawing a proposal from the prior distribution. After each proposal, the model is evaluated and the likelihood is calculated. If the likelihood $\left(\mathcal{L}_{P}\right)$ is greater than or equal to the likelihood of the last accepted proposal $\left(\mathcal{L}_{A}\right)$, the proposed parameter value is automatically accepted into the posterior. However if this likelihood is less, it is passed to a secondary criterion for acceptance. If the quotient of $\left(\mathcal{L}_{P}\right)$ divided by $\left(\mathcal{L}_{A}\right)$ is greater than a random number drawn on the interval $[0,1]$, then the proposal is accepted into the posterior. Equation (5.5) represents this criteria.

$$
\text { IF }: \frac{\mathcal{L}_{P}}{\mathcal{L}_{A}} \geq \operatorname{rand}[0,1] \rightarrow \text { Accept }
$$

If the proposal is accepted, the prior distribution for that parameter is then centered at the proposed value. Thus since the priors for $\theta$ are bounded normal distributions, the mean of the distribution shifts to the last accepted value. After a proposal has either been accepted or denied, Gibbs sampling is preformed on the observational error's prior, as discussed previously.

This procedure continues in a loop until the desired number of MCMC steps are completed. The uncertainty quantification process is complete once two conditions are satisfied. First condition for completion is that "burn in" is achieved. Burn in refers to the beginning of the process when each parameter travels from its initial starting point to its optimal area. Figure (5.1) illustrates the burn in processes. 


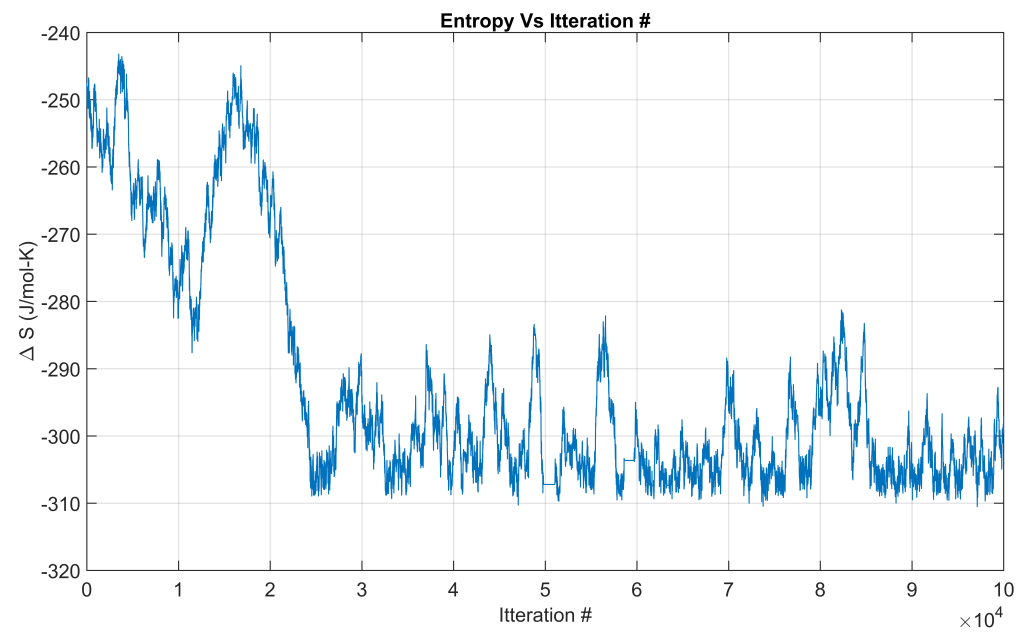

Figure 5.1: Illustration of burn in

Once each parameter has burned in, a batch means test must be performed on the posterior to ensure convergence. Batch means test divides the posterior into "batches" or groups and then calculates the mean of each groups. Then these means are then compared to check for convergence. This make sure the posterior distribution has converged.

Finally, the result will be the posterior distribution for all model parameters. This distribution contains considerable information about the model, technology, and experiment. First off if the distribution is very narrow or tight for a parameter, there is a lot of confidence with this estimation. However if the posterior is very broad, then there is a good deal of uncertainty associated with this parameter. This provides information for better experiments to be designed. Also as these results are extrapolated to a larger scale model, there is an idea of the uncertainty that is attached to that extrapolation. The posterior will also contain information about the relationship of parameters with each other, for example if two parameters are correlated. Lastly using the resultant posterior and mathematical model, the predictions will cover the real data, meaning that the "real parameters" are contained in the posterior. 


\section{Chapter 6}

\section{Results and Discussion}

\subsection{Introduction}

Using the methodology discussed in previous chapters, uncertainty quantification was performed on a test case for the fixed bed model.

\subsection{Data Generation}

Due to a lack of available experimental data for this experiment, data was generated using the model with chosen "real" parameters. The data set generated used $20 \% \mathrm{CO}_{2}$ and $9 \%$ $\mathrm{H}_{2} \mathrm{O}$, and the bed was maintained at $298 \mathrm{~K}$. Once the data set was generated, white noise was added to the data in order to simulate the noise and error in actual experiment. The values used to create this data set located in the Table (6.1). These are the "real" values for the parameters. 
Table 6.1: Parameters for data set

\begin{tabular}{||c|c|c|c|c|c||}
\hline Parameter & Value & Parameter & Value & Parameter & Value \\
\hline$\Delta H_{c}$ & $-115.8\left(\frac{\mathrm{kJ}}{\mathrm{mol}}\right)$ & $\Delta H_{h}$ & $-67.25\left(\frac{\mathrm{kJ}}{\mathrm{mol}}\right)$ & $\Delta H_{b}$ & $-110.1\left(\frac{\mathrm{kJ}}{\mathrm{mol}}\right)$ \\
\hline$\Delta S_{c}$ & $-298.3\left(\frac{\mathrm{J}}{\mathrm{mol}-K}\right)$ & $\Delta S_{h}$ & $-124.9\left(\frac{\mathrm{J}}{\mathrm{mol}-K}\right)$ & $\Delta S_{b}$ & $-162.96\left(\frac{\mathrm{J}}{\mathrm{mol}-K}\right)$ \\
\hline$\Delta H_{c}^{\ddagger}$ & $54.28\left(\frac{\mathrm{kJ}}{\mathrm{mol}}\right)$ & $\Delta H_{h}^{\ddagger}$ & $59.60\left(\frac{\mathrm{kJ}}{\mathrm{mol}}\right)$ & $\Delta H_{b}^{\ddagger}$ & $106.3\left(\frac{\mathrm{kJ}}{\mathrm{mol}}\right)$ \\
\hline$\zeta_{c}$ & $0.869422(\mathrm{~N} / \mathrm{A})$ & $\zeta_{h}$ & $2.00(\mathrm{~N} / \mathrm{A})$ & $\zeta_{b}$ & $1.89(\mathrm{~N} / \mathrm{A})$ \\
\hline$n_{v}$ & $1882.68\left(\frac{\mathrm{mol}}{\mathrm{m}^{3}}\right)$ & $n_{h}$ & $2382.68\left(\frac{\mathrm{mol}}{\mathrm{m}^{3}}\right)$ & $M$ & $1.39 \times 10^{-4}$ \\
\hline \hline
\end{tabular}

Below are the figures of the simulated data set (Pressure Drop, $\mathrm{CO}_{2} \%, \mathrm{H}_{2} \mathrm{O} \%$ ) along with the added white noise. 

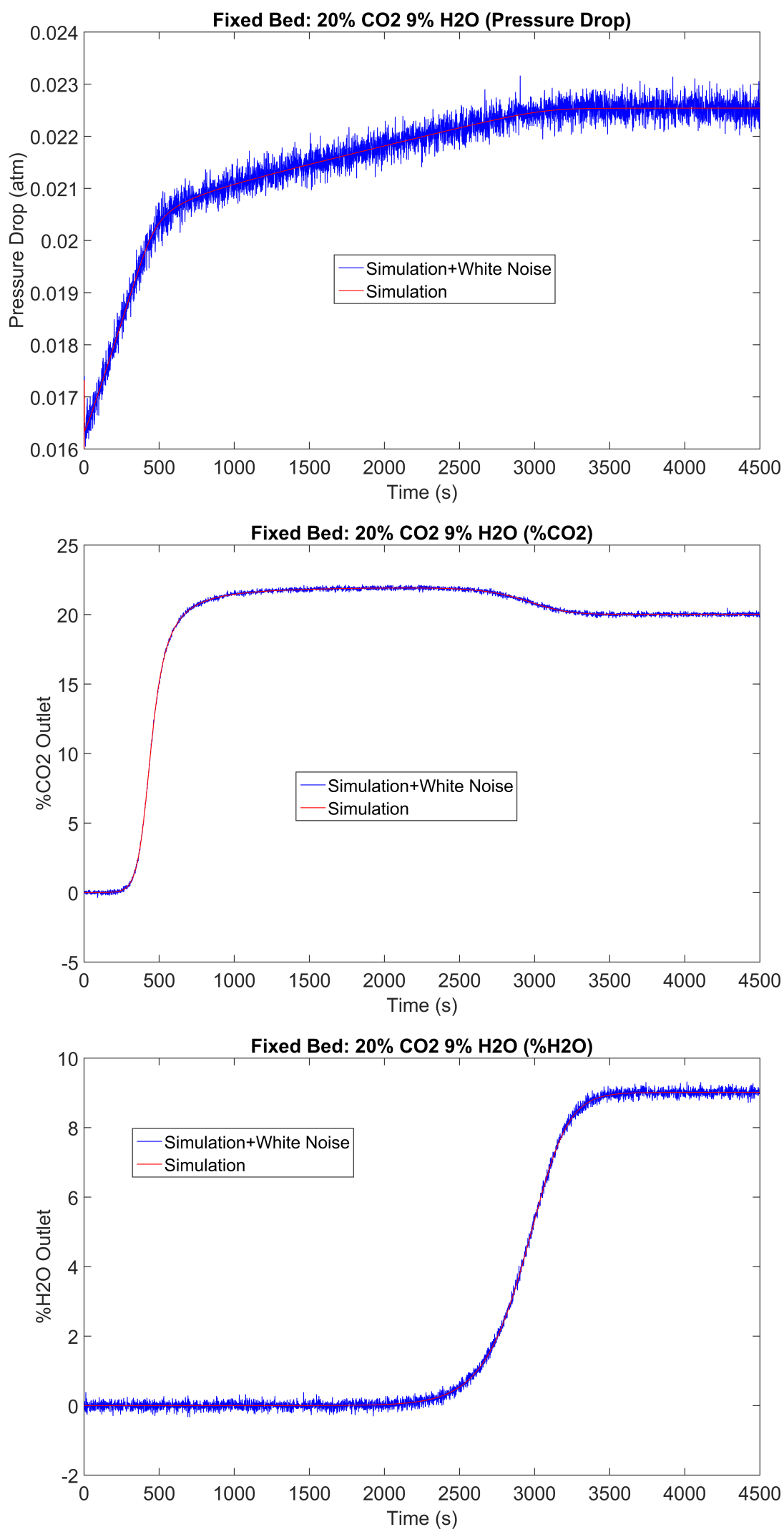

Figure 6.1: Generated experimental data sets 


\subsection{Fixed Bed Posterior}

The results for the fixed bed posterior will now be discussed. First the priors used for this analysis will be presented. Then the posterior results will be discussed. There are two types of results that were obtained from this analysis. The first is the comparison of the posterior predictions with the reality data. The second is the posterior distribution for the model parameters.

\subsubsection{Parameter Priors}

Uniform normal distributions were used for the priors of parameters $\theta$. Table (6.2) shows standard deviation of each prior.

Table 6.2: Parameter priors

\begin{tabular}{||c|c|c|c|c|c||}
\hline Parameter & $\sigma$ & Parameter & $\sigma$ & Parameter & $\sigma$ \\
\hline$\Delta H_{c}$ & $1500\left(\frac{J}{\mathrm{~mol}}\right)$ & $\Delta H_{h}$ & $2000\left(\frac{\mathrm{J}}{\mathrm{mol}}\right)$ & $\Delta H_{b}$ & $28000\left(\frac{\mathrm{J}}{\mathrm{mol}}\right)$ \\
\hline$\Delta S_{c}$ & $40\left(\frac{\mathrm{J}}{\mathrm{mol}-K}\right)$ & $\Delta S_{h}$ & $25\left(\frac{\mathrm{J}}{\mathrm{mol}-K}\right)$ & $\Delta S_{b}$ & $210\left(\frac{\mathrm{J}}{\mathrm{mol}-K}\right)$ \\
\hline$\Delta H_{c}^{\ddagger}$ & $800\left(\frac{\mathrm{J}}{\mathrm{mol}}\right)$ & $\Delta H_{h}^{\ddagger}$ & $2000\left(\frac{J}{\mathrm{~mol}}\right)$ & $\Delta H_{b}^{\ddagger}$ & $28000\left(\frac{\mathrm{J}}{\mathrm{mol}}\right)$ \\
\hline$\zeta_{c}$ & $.025(\mathrm{~N} / \mathrm{A})$ & $\zeta_{h}$ & $.07(\mathrm{~N} / \mathrm{A})$ & $\zeta_{b}$ & $5.1(\mathrm{~N} / \mathrm{A})$ \\
\hline$n_{v}$ & $15\left(\frac{\mathrm{mol}}{\mathrm{m}^{3}}\right)$ & $n_{h}$ & $15\left(\frac{\mathrm{mol}}{\mathrm{m}^{3}}\right)$ & $M$ & $2.5 \times 10^{-6}$ \\
\hline \hline
\end{tabular}

\subsubsection{Reality Coverage}

An important result is to ensure that the model predictions of the posterior cover the real data. For the fixed bed model, there are three sets of real data that are compared to per experiment. The first is the pressure drop across the bed. This pressure drop curve provides information on the mobility parameter as well as the adsorption parameters. 


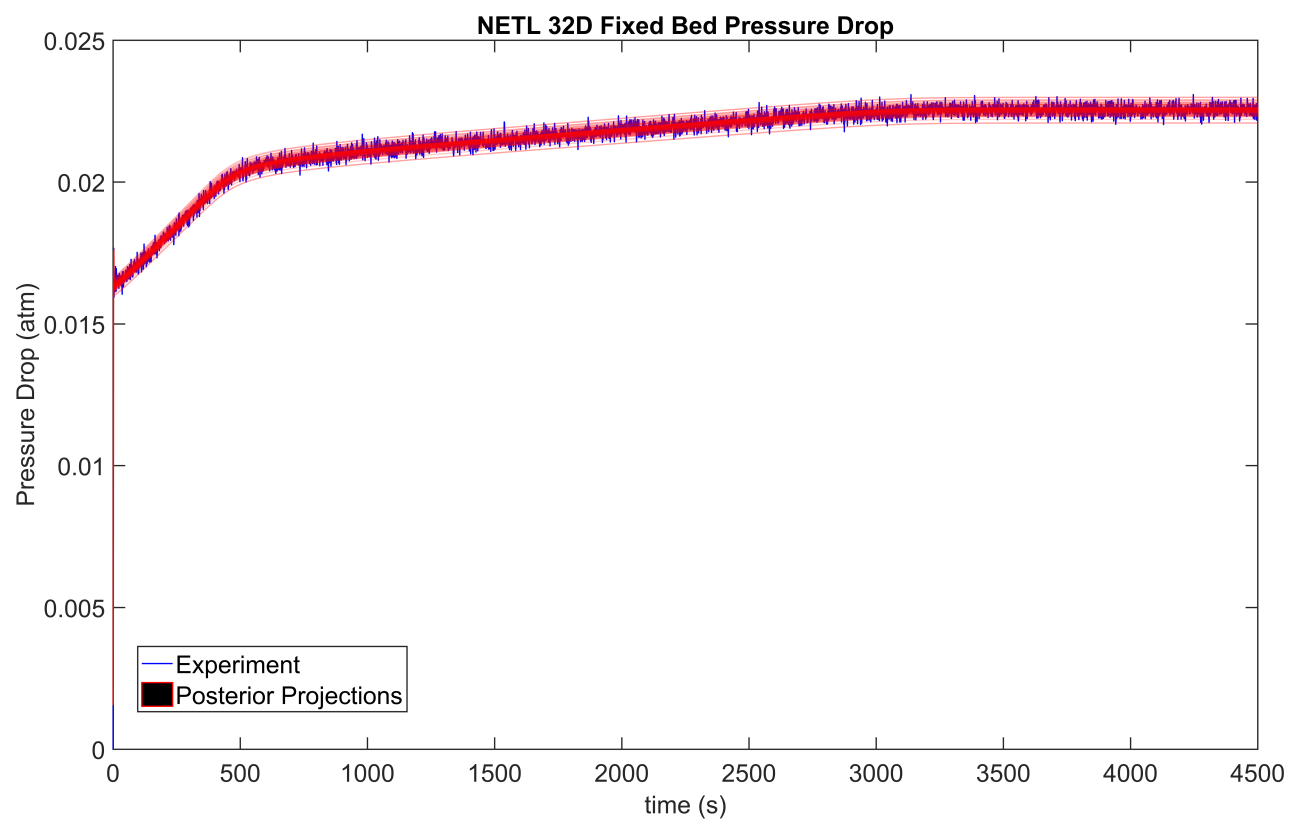

Figure 6.2: Posterior model pressure drop predictions

As shown, the model predictions cover the pressure drop curve. The second data set is the $\mathrm{CO}_{2} \%$ at the outlet. This breakthrough curve contains much information about the carbamate and bicarbonate reactions.

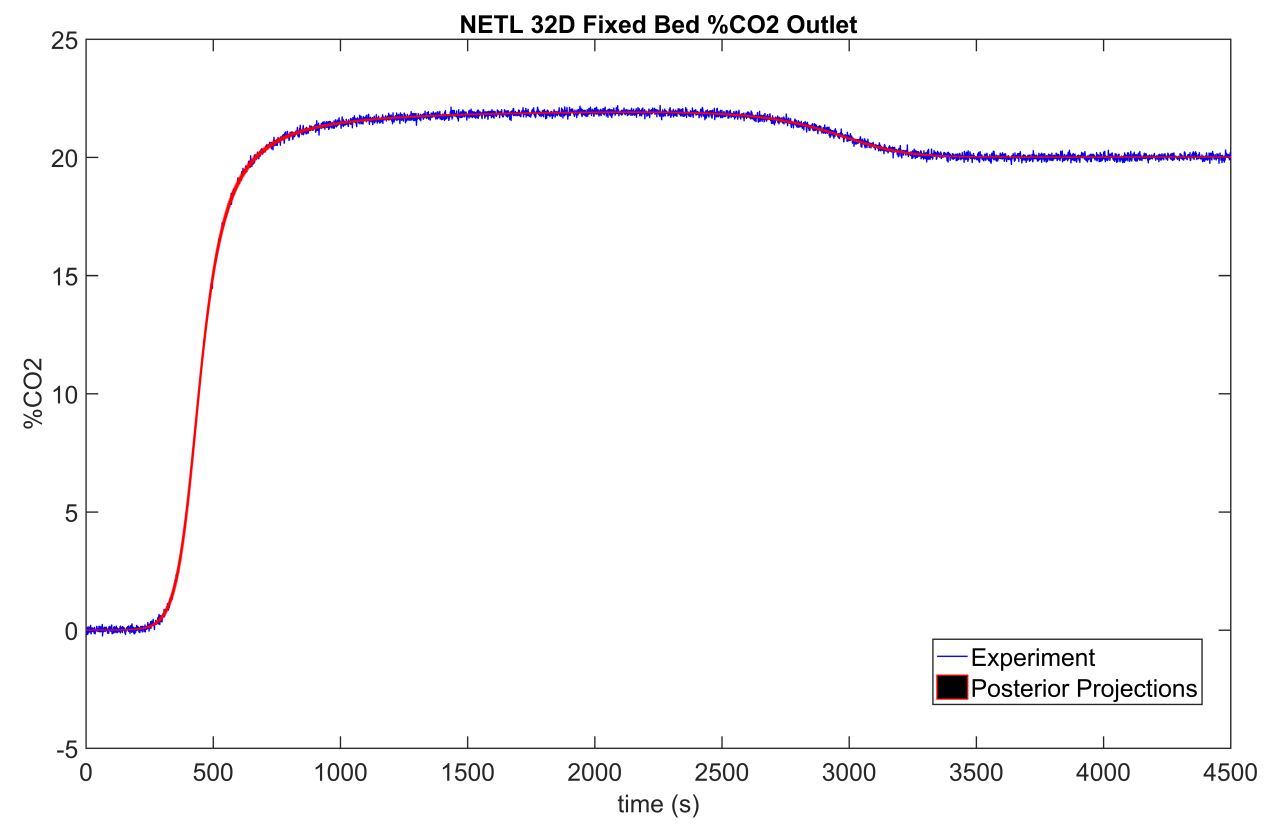

Figure 6.3: Posterior model $\mathrm{CO}_{2} \%$ outlet predictions 
As shown, the model predictions cover the breakthrough curve of $\mathrm{CO}_{2}$. The next figure is zoomed in on the main area of interest. This shows the posterior predictions covering both sides of the curve, meaning that the real values are contained in the posterior.

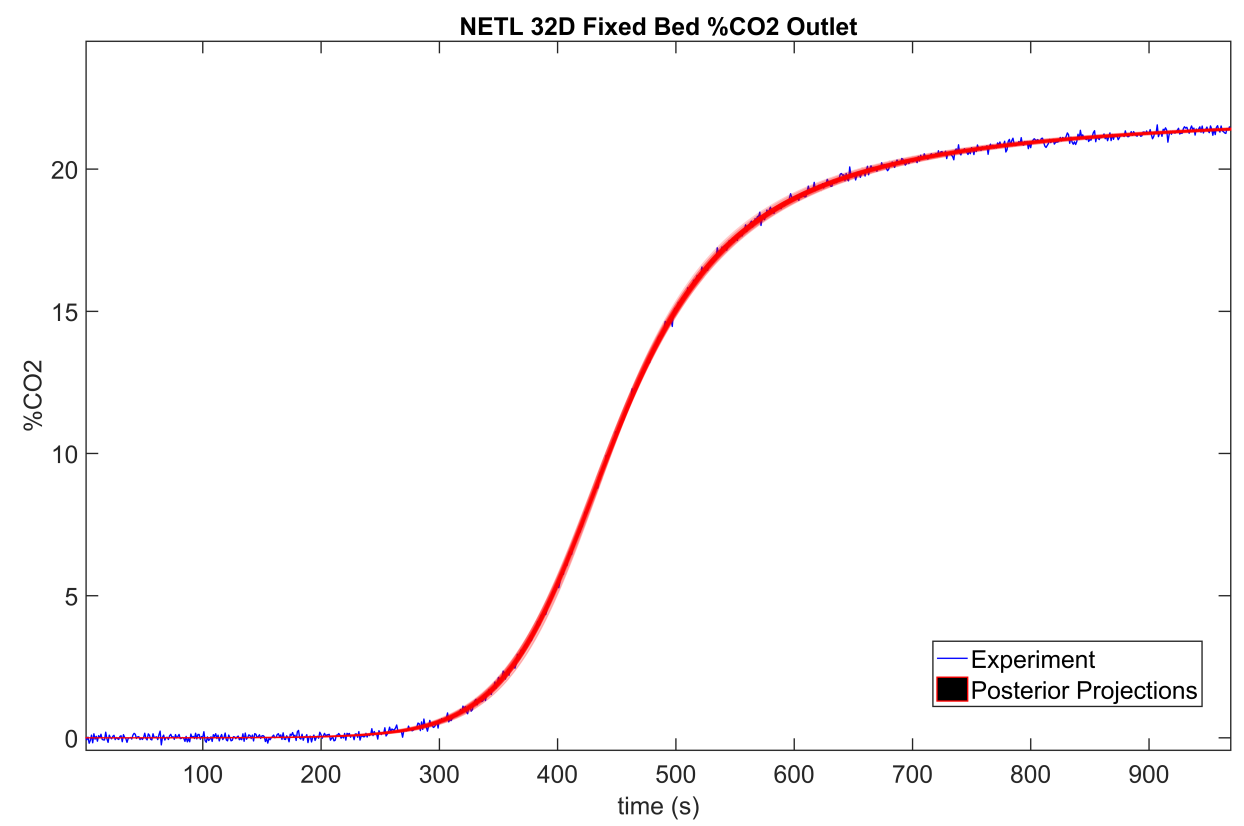

Figure 6.4: Posterior model $\mathrm{CO}_{2} \%$ outlet predictions zoomed in

The last data set is the $\mathrm{H}_{2} \mathrm{O} \%$ outlet breakthrough curve. This provides information about water adsorption and bicarbonate formation as well. Figure (6.5) shows the results of the posterior model predictions for the $\mathrm{H}_{2} \mathrm{O} \%$ Outlet breakthrough curve. 


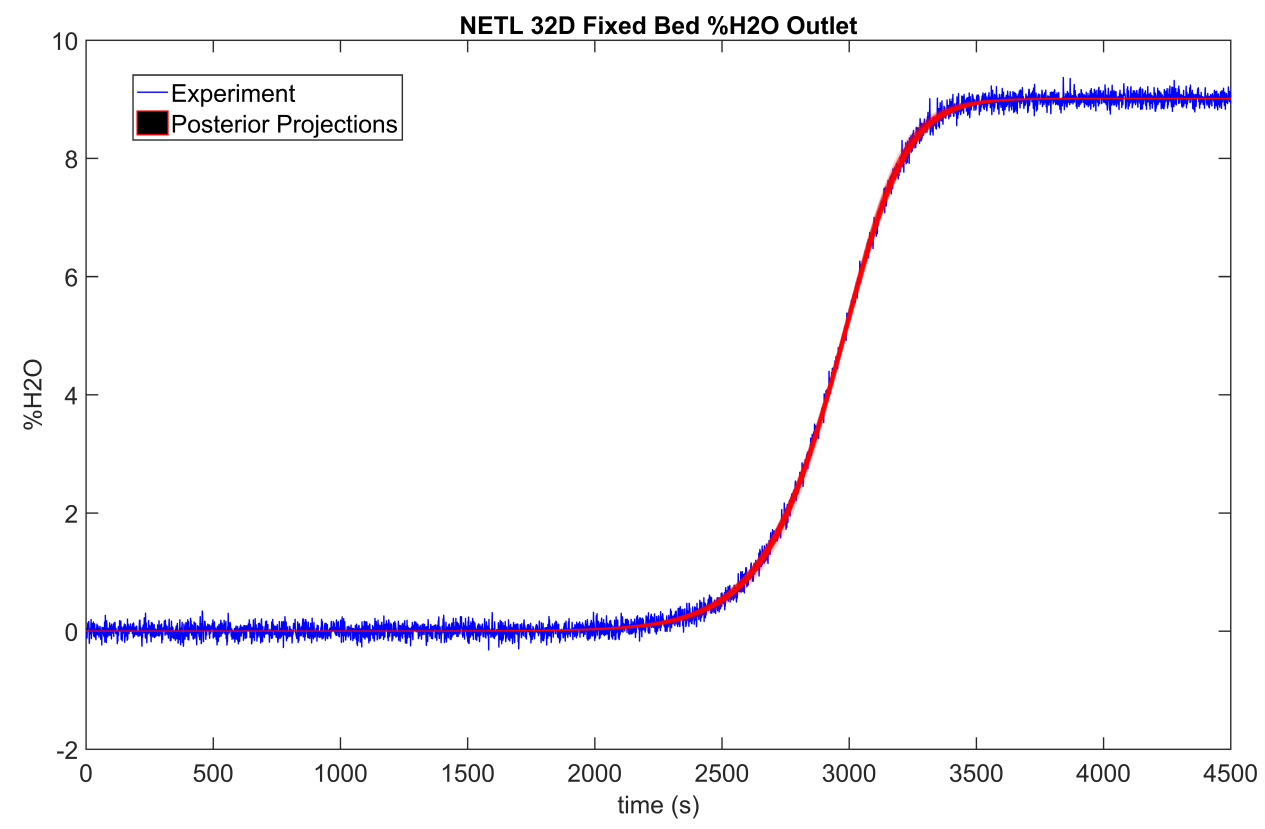

Figure 6.5: Posterior model $\mathrm{H}_{2} \mathrm{O} \%$ outlet predictions

There is adequate coverage here as well. To illustrate this better, Figure (6.6) is zoomed in on the most important section of the curve. This shows the posterior predictions covering both sides of the curve, meaning that the real values are contained in the posterior.

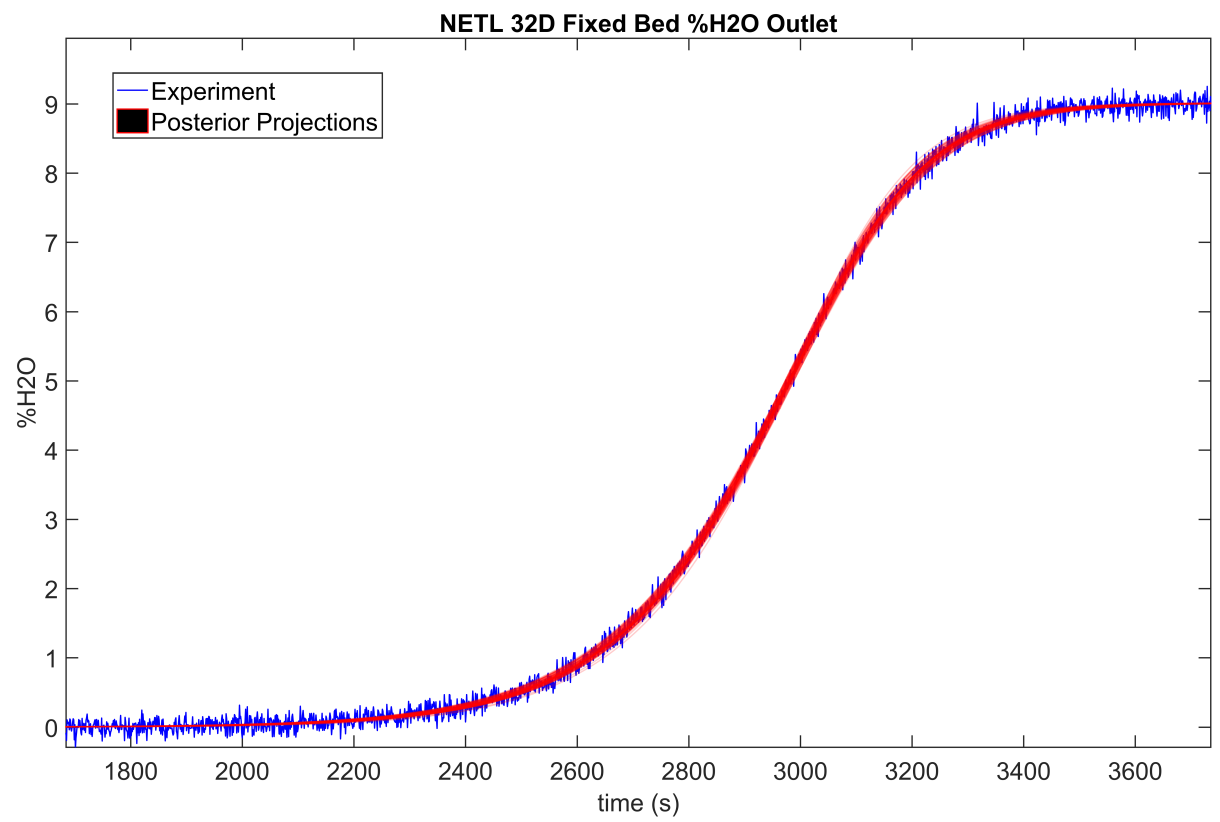

Figure 6.6: Posterior model $\mathrm{H}_{2} \mathrm{O} \%$ outlet predictions zoomed in 
The five previous plots show that the posterior distribution for the analysis done does contain the real values for these parameters. They are contained in this posterior. Now the posterior its self will be examined. 


\subsubsection{Parameter Analysis}

\section{Carbamate}

Below is a figure of the posterior distributions for the carbamate parameters. The real parameter value is marked with a red "o" in the posterior of each parameter posterior.
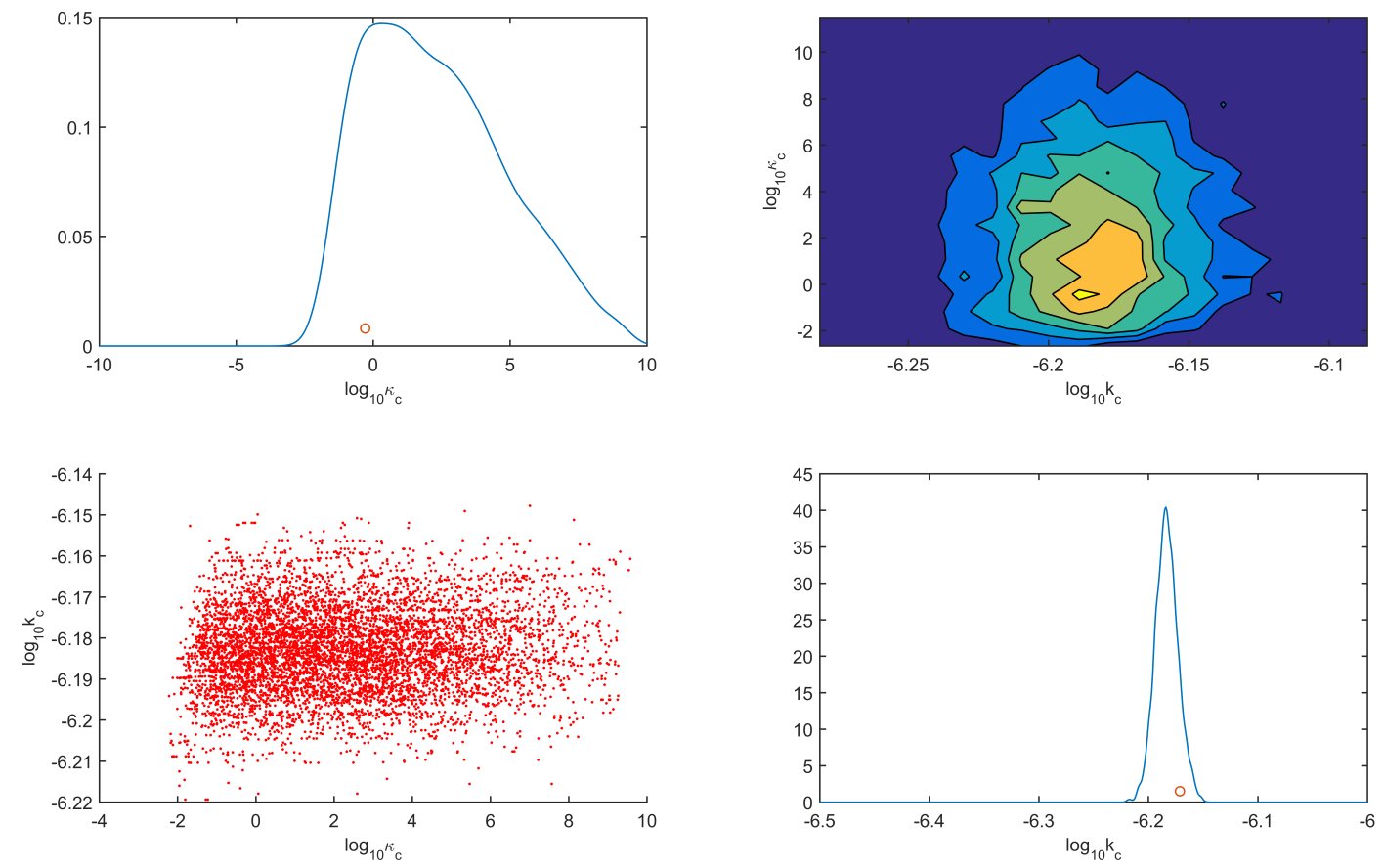

Figure 6.7: Posterior distributions for carbamate formation

Figure (6.7) shows that a very tight distribution for the rate constant was observed. However the posterior for the equilibrium constant is very broad, which means there is a lot of uncertainty for these equilibrium parameters. 


\section{Water}

Figure(6.8) shows the posterior distributions for the equilibrium and rate constants for water physisorption. The real parameter value is marked with a red "o" in the posterior of each parameter posterior.
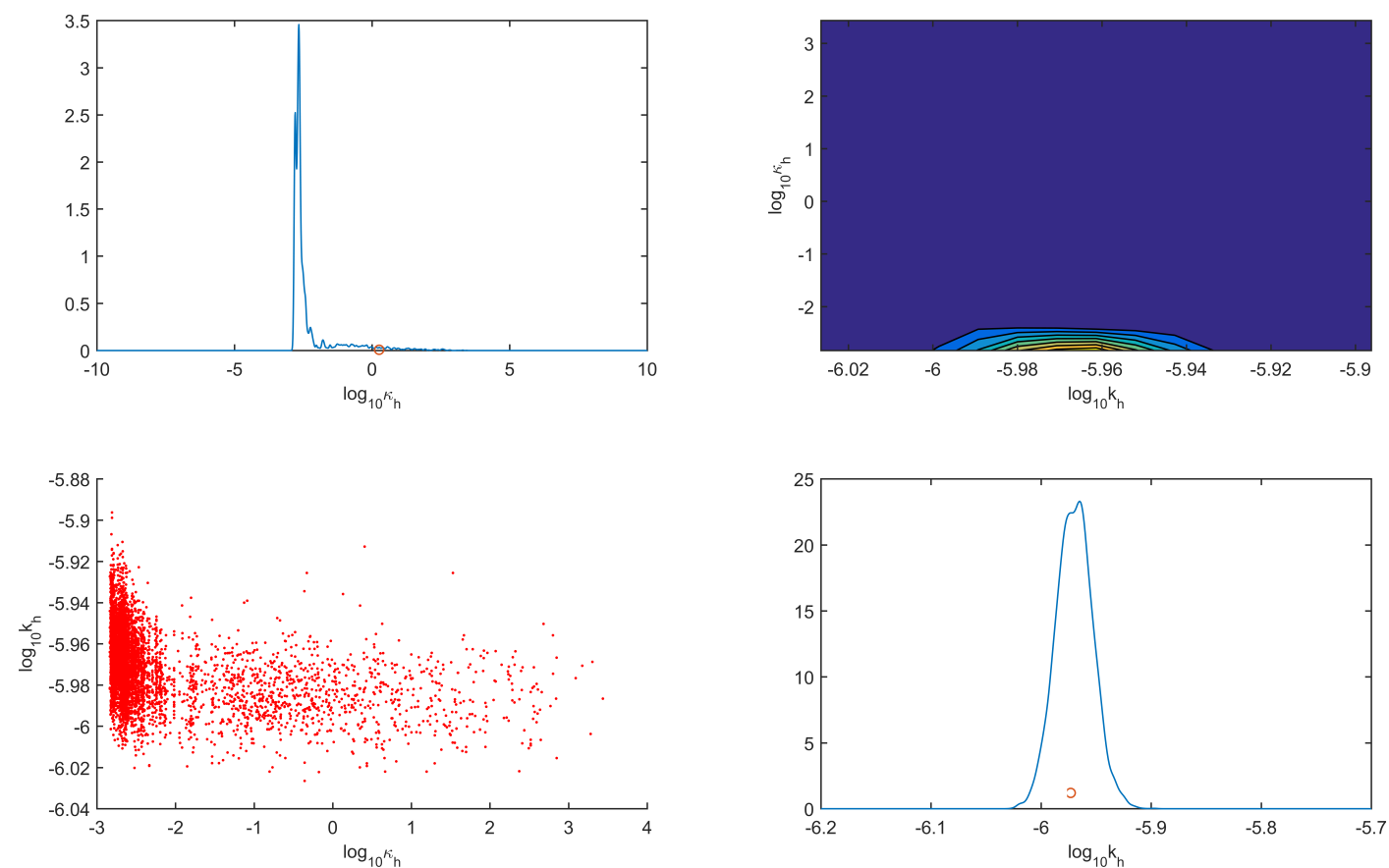

Figure 6.8: Posterior distributions for water adsorption

As shown above, there is a good amount of certainty with the estimations for the water adsorption parameters. Decent certainty in the equilibrium constant was observed, while excellent certainty was found in the rate constant estimation. 


\section{Bicarbonate}

Figure(6.9) is the posterior distributions for the equilibrium and rate constants for bicarbonate formation. The real parameter value is marked with a red "o" in the posterior of each parameter posterior.
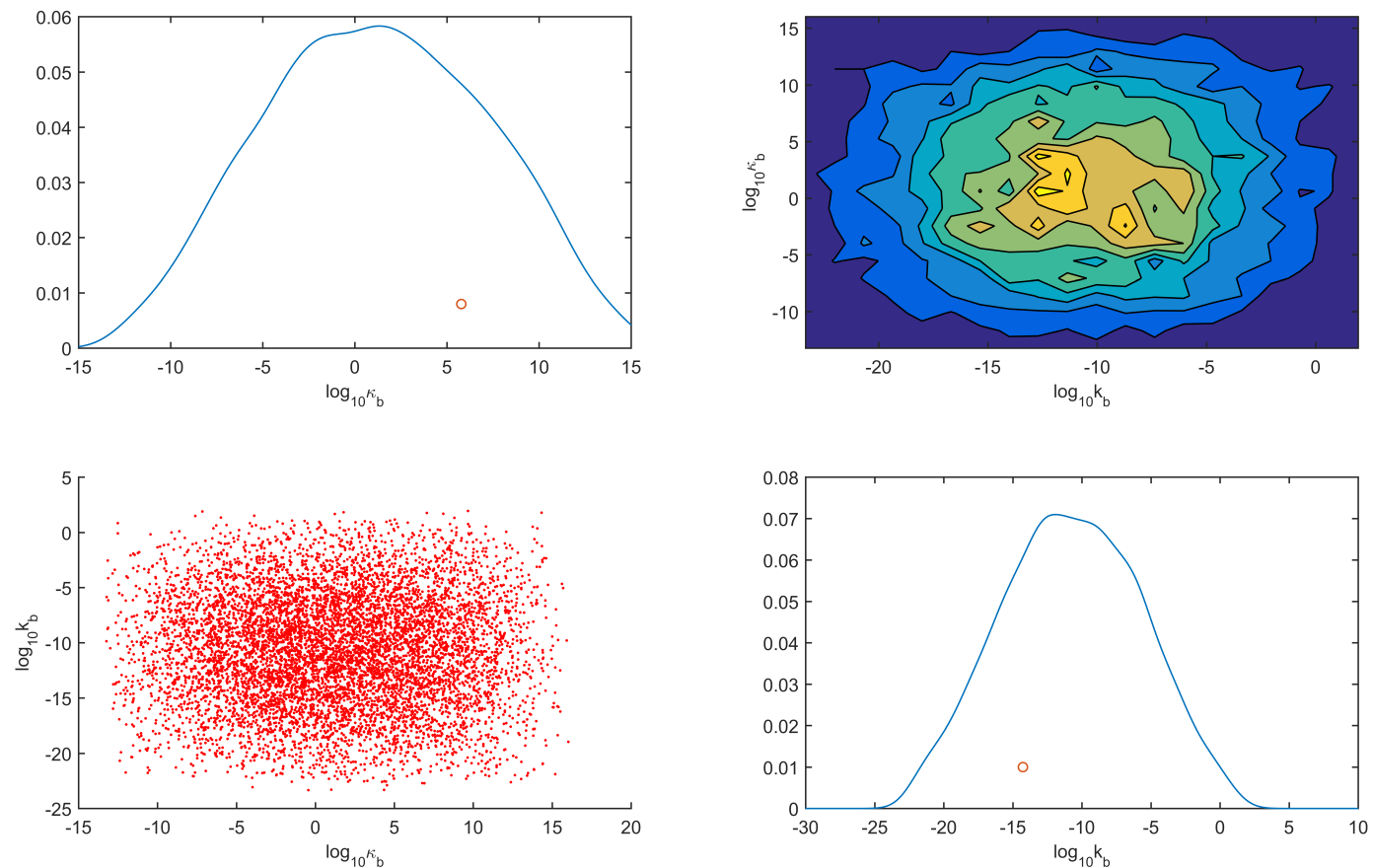

Figure 6.9: Posterior distributions for bicarbonate formation

As shown above, there is much uncertainty associated with the bicarbonate parameters. This was also found in the TGA analysis. 


\section{Adsorption Site Densities}

Figure(6.10) is the posterior distributions for the two site density parameters. The real parameter value is marked with a red "o" in the posterior of each parameter posterior.
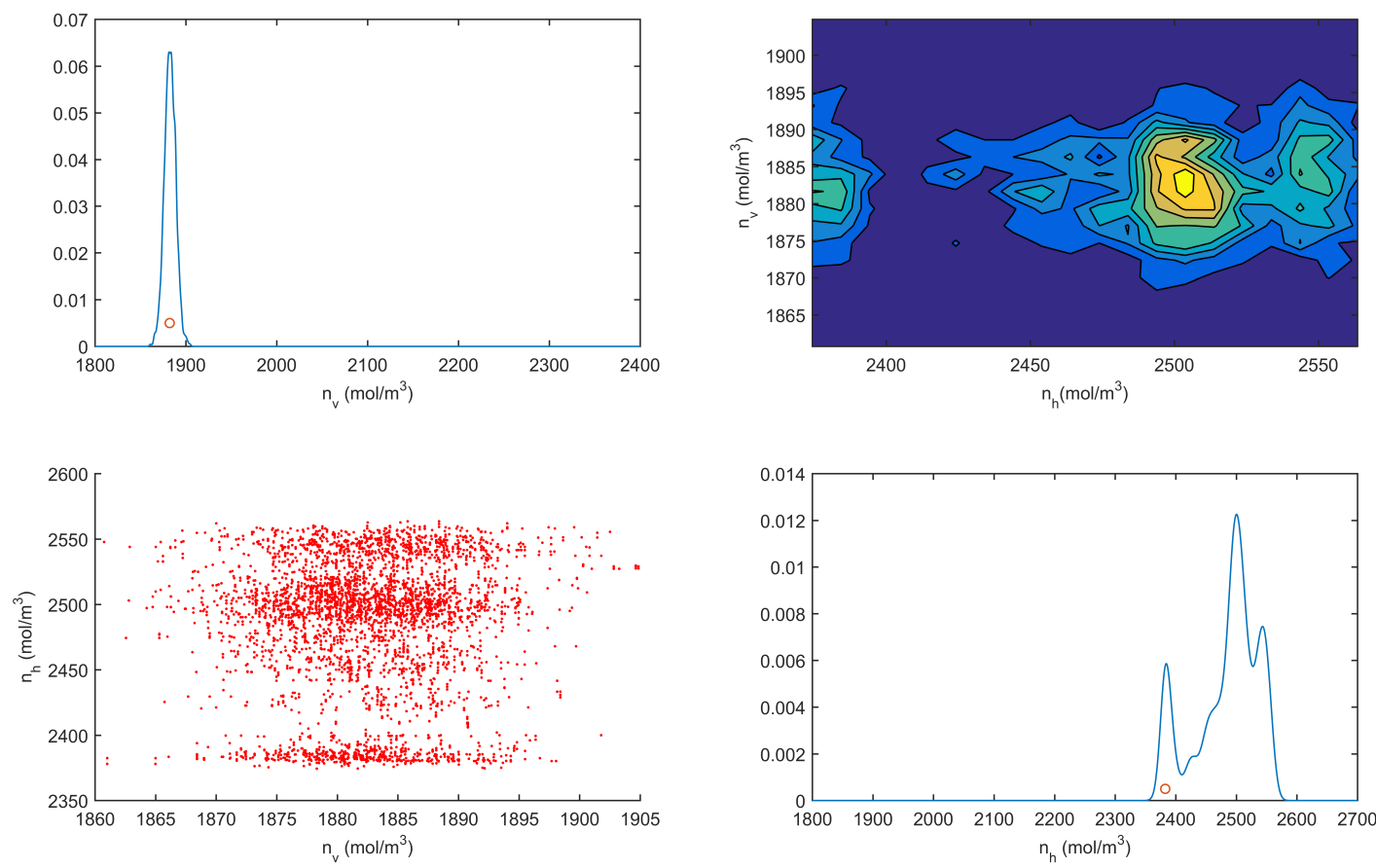

Figure 6.10: Posterior distributions for site densities

As shown above, the site densities have tight posterior distributions. This means there is a lot of certainty associated with these estimations. 


\section{Mobility}

Figure(6.11) is the posterior distributions for the mobility parameter, with the real value represented with a red "o".

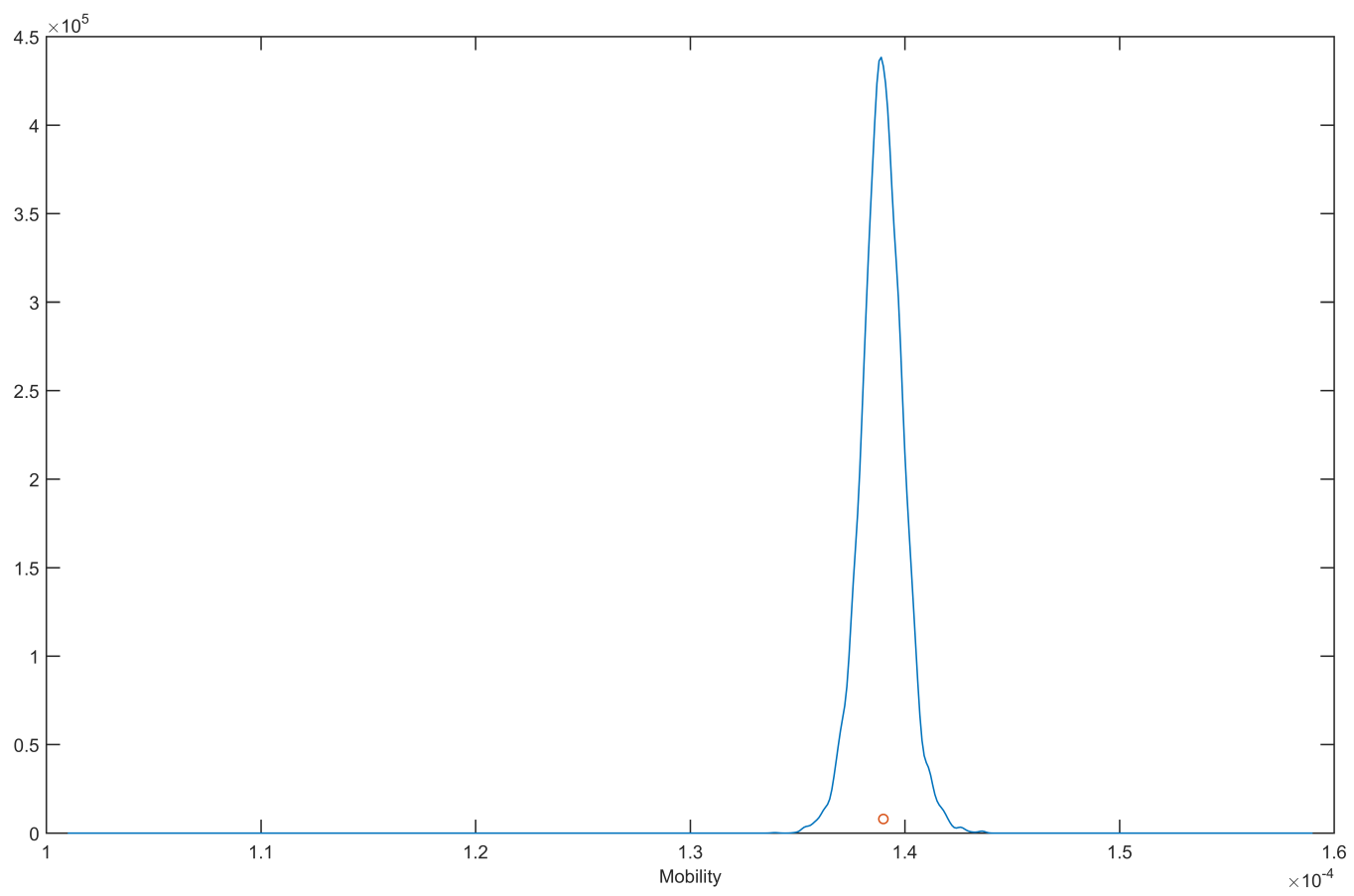

Figure 6.11: Posterior distributions for the mobility parameter

For the mobility parameter, it was found to have a very narrow posterior. Also, the posterior is completely centered around the true value used to create the data set. 
Table (6.3) contains the site densities, mobility, equilibrium, and rate constants used to create the generated data. These are the "real" values for the data set.

Table 6.3: Real values for equilibrium and rate constants of data

\begin{tabular}{||c|c|c|c|c|c||}
\hline Parameter & Value & Parameter & Value & Parameter & Value \\
\hline $\log _{10}\left(\kappa_{c}\right)$ & -.2892 & $\log _{10}\left(\kappa_{h}\right)$ & .2582 & $\log _{10}\left(\kappa_{b}\right)$ & 5.7813 \\
\hline $\log _{10}\left(k_{c}\right)$ & -6.1711 & $\log _{10}\left(k_{h}\right)$ & -5.9731 & $\log _{10}\left(k_{b}\right)$ & -14.2691 \\
\hline$n_{v}$ & $1882.68\left(\frac{m o l}{m^{3}}\right)$ & $n_{h}$ & $2382.68\left(\frac{m o l}{m^{3}}\right)$ & $M$ & $1.39 \times 10^{-4}$ \\
\hline \hline
\end{tabular}

Table (6.4) shows the standard deviation $(\sigma)$ and mean $(\mu)$ of each parameter's posterior.

Table 6.4: Fixed bed posterior properties

\begin{tabular}{||c|c|c|c|c|c||}
\hline Parameter & $\sigma$ & $\mu$ & Parameter & $\sigma$ & $\mu$ \\
\hline $\log _{10}\left(\kappa_{c}\right)$ & 2.5323 & 2.3149 & $\log _{10}\left(k_{c}\right)$ & .0104 & -6.1832 \\
\hline $\log _{10}\left(\kappa_{h}\right)$ & .9348 & -2.3069 & $\log _{10}\left(k_{h}\right)$ & .0166 & -5.9697 \\
\hline $\log _{10}\left(\kappa_{b}\right)$ & 5.9911 & 1.1725 & $\log _{10}\left(k_{b}\right)$ & 5.0216 & -10.7488 \\
\hline$n_{v}\left(\frac{m o l}{m^{3}}\right)$ & 6.2706 & 1882.6 & $n_{h}\left(\frac{m o l}{m^{3}}\right)$ & 51.7315 & 2485.1 \\
\hline$M$ & $1.0043 \times 10^{-6}$ & $1.3895 \times 10^{-4}$ & & & \\
\hline \hline
\end{tabular}

Table (6.5) shows the convergence confidence results for the posterior distribution from the batch means test.

Table 6.5: Fixed bed posterior convergence confidence

\begin{tabular}{||c|c|c|c||}
\hline Parameter & Confidence & Parameter & Confidence \\
\hline $\log _{10}\left(\kappa_{c}\right)$ & $\pm 7.5 \%$ & $\log _{10}\left(k_{c}\right)$ & $\pm 0.01 \%$ \\
\hline $\log _{10}\left(\kappa_{h}\right)$ & $\pm 7.45 \%$ & $\log _{10}\left(k_{h}\right)$ & $\pm 0.02 \%$ \\
\hline $\log _{10}\left(\kappa_{b}\right)$ & $\pm 19.73 \%$ & $\log _{10}\left(k_{b}\right)$ & $\pm 1.52 \%$ \\
\hline$n_{v}\left(\frac{m o l}{m^{3}}\right)$ & $\pm 0.02 \%$ & $n_{h}\left(\frac{m o l}{m^{3}}\right)$ & $\pm 0.24 \%$ \\
\hline$M$ & $\pm 0.03 \%$ & & \\
\hline
\end{tabular}




\section{Chapter 7}

\section{Conclusions \& Accomplishments}

From the results in Chapter 6, a few conclusions can be drawn from this work. The ultimate goal of this work was completed and demonstrated. The CCSI tool set for multi scale modeling was expanded to include analysis of the fixed bed reactor experiment for both parameter estimation and uncertainty quantification. The demonstration showed that when analyzing a generated data set, the posterior distribution covers the reality as well as quantifying the uncertainty with the estimations. Another conclusion is that fixed bed reactors contain more kinetic information. More certainty was found for kinetic parameters associated with adsorption reactions. Lastly, different experiments can be conducted to obtain more certainty, such as changing the ratio of $\mathrm{CO}_{2} \& \mathrm{H}_{2} \mathrm{O}$ or by varying the temperature of the gas. 


\section{Acknowledgments}

I would like to gratefully thank the following for the help and support throughout this endeavor:

First and foremost, I would like to thank God for all that he has done in my life. I am a very blessed man for his teachings, love, and grace. His never ending grace has allowed me to grow in the person I have become. For all of his grace and mercy I am eternally thankful!

I would like to thank Dr. David Mebane for serving as my advisor and mentor. You have provided me with countless assistance and encouragement. You have taught me more than I could have ever asked for. I would like to thank Dr. Debangsu Bhattacharyya \& Dr. Kenneth Means for agreeing being on my committee and being available for assistance if needed. Thank you all!

I especially want to thank my loving wife, Katlyn, for her love, support, and never ending encouragement. You have been my rock through my whole graduate school career. I can not thank you enough for all of your prayers, thoughts, and care! Next I would like to thank my parents, Brian and Wendy Logsdon, and my brother, Seth, for their love and support throughout my collegiate career. You were always there and never hesitated if I ever needed anything. I am blessed to have such a wonderful family! Thank you and I love you all dearly!

Last but not least, I would like to thank my research group (alumni and current members) for providing a supportive environment in which we all have been able to achieve success. You all have been a blast to work with and I am very blessed to have gotten to know each and everyone of you! I wish you all the best in your future endeavors! 


\section{Bibliography}

[1] United States Environmental Protection Agency. Overview of greenhouse gases, 2016. 2016-03-24.

[2] Farminder S Anand, Jay H Lee, and Matthew J Realff. Decision oriented bayesian design of experiments. In Advanced Control of Chemical Processes, volume 7, pages 655-660, 2009.

[3] Rahul Banerjee, Hiroyasu Furukawa, David Britt, Carolyn Knobler, Michael O’Keeffe, and Omar M Yaghi. Control of pore size and functionality in isoreticular zeolitic imidazolate frameworks and their carbon dioxide selective capture properties. Journal of the American Chemical Society, 131(11):3875-3877, 2009.

[4] Rahul Banerjee, Anh Phan, Bo Wang, Carolyn Knobler, Hiroyasu Furukawa, Michael O'Keeffe, and Omar M Yaghi. High-throughput synthesis of zeolitic imidazolate frameworks and application to co2 capture. Science, 319(5865):939-943, 2008.

[5] David Britt, Hiroyasu Furukawa, Bo Wang, T Grant Glover, and Omar M Yaghi. Highly efficient separation of carbon dioxide by a metal-organic framework replete with open metal sites. Proceedings of the National Academy of Sciences, 106(49):20637-20640, 2009.

[6] Thiam-Leng Chew, Abdul L Ahmad, and Subhash Bhatia. Ordered mesoporous silica (oms) as an adsorbent and membrane for separation of carbon dioxide (co 2). Advances in Colloid and Interface Science, 153(1):43-57, 2010. 
[7] Siddhartha Chib and Edward Greenberg. Understanding the metropolis-hastings algorithm. The american statistician, 49(4):327-335, 1995.

[8] Sunho Choi, Jeffrey H Drese, and Christopher W Jones. Adsorbent materials for carbon dioxide capture from large anthropogenic point sources. ChemSusChem, 2(9):796-854, 2009.

[9] Denis Clodic, Rima El Hitti, Mourad Younes, Alain Bill, and François Casier. Co2 capture by anti-sublimation thermo-economic process evaluation. In 4th Annual Conference on Carbon Capture and Sequestration, pages 2-5. National Energy Technology Laboratory Alexandria^eVA VA, 2005.

[10] Benoit Coasne, Francisco R Hung, Roland J-M Pellenq, Flor R Siperstein, and Keith E Gubbins. Adsorption of simple gases in mcm-41 materials: the role of surface roughness. Langmuir, 22(1):194-202, 2006.

[11] Paolo Davini. Flue gas treatment by activated carbon obtained from oil-fired fly ash. Carbon, 40(11):1973-1979, 2002.

[12] TC Drage, A Arenillas, Karl M Smith, and Colin E Snape. Thermal stability of polyethylenimine based carbon dioxide adsorbents and its influence on selection of regeneration strategies. Microporous and mesoporous materials, 116(1):504-512, 2008.

[13] Enrico Drioli, Efrem Curcio, and Enrica Fontananova. Mass Transfer OperationMembrane Separations. Eolss Publishers: Oxford, UK, 2006.

[14] Bandar Fadhel, Milton Hearn, and Alan Chaffee. Co 2 adsorption by pamam dendrimers: significant effect of impregnation into sba-15. Microporous and Mesoporous Materials, 123(1):140-149, 2009. 
[15] Robert S Franchi, Peter JE Harlick, and Abdelhamid Sayari. Applications of poreexpanded mesoporous silica. 2. development of a high-capacity, water-tolerant adsorbent for co2. Industrial \&3 Engineering Chemistry Research, 44(21):8007-8013, 2005.

[16] Walter R Gilks, Sylvia Richardson, and David J Spiegelhalter. Introducing markov chain monte carlo. Markov chain Monte Carlo in practice, 1:19, 1996.

[17] ML Gray, Y Soong, KJ Champagne, H Pennline, JP Baltrus, RW Stevens, R Khatri, SSC Chuang, and T Filburn. Improved immobilized carbon dioxide capture sorbents. Fuel Processing Technology, 86(14):1449-1455, 2005.

[18] Murlidhar Gupta, Irene Coyle, and Kelly Thambimuthu. Co2 capture technologies and opportunities in canada. In 1st Canadian CCESS Technology Roadmap Workshop, volume 18, page 19, 2003.

[19] Peter JE Harlick and Abdelhamid Sayari. Applications of pore-expanded mesoporous silica. 5. triamine grafted material with exceptional co2 dynamic and equilibrium adsorption performance. Industrial \& Engineering Chemistry Research, 46(2):446-458, 2007.

[20] Jason C Hicks, Jeffrey H Drese, Daniel J Fauth, McMahan L Gray, Genggeng Qi, and Christopher W Jones. Designing adsorbents for co2 capture from flue gas-hyperbranched aminosilicas capable of capturing co2 reversibly. Journal of the American Chemical Society, 130(10):2902-2903, 2008.

[21] TA Instruments. Q600 sdt thermo gravimetric analyzer, 2016. 2016-03-28.

[22] Koichi Kajihara, Shungo Kuwatani, Ryohei Maehana, and Kiyoshi Kanamura. Macroscopic phase separation in a tetraethoxysilane-water binary sol-gel system. Bulletin of the Chemical Society of Japan, 82(12):1470-1476, 2009. 
[23] J. Kennedy and R. Eberhart. Particle swarm optimization. volume 4, pages 1942-1948 vol.4, 1995.

[24] Marc C Kennedy and Anthony O'Hagan. Bayesian calibration of computer models. Journal of the Royal Statistical Society: Series B (Statistical Methodology), 63(3):425464, 2001.

[25] Ryan J Kuppler, Daren J Timmons, Qian-Rong Fang, Jian-Rong Li, Trevor A Makal, Mark D Young, Daqiang Yuan, Dan Zhao, Wenjuan Zhuang, and Hong-Cai Zhou. Potential applications of metal-organic frameworks. Coordination Chemistry Reviews, 253(23):3042-3066, 2009.

[26] Orlando Leal, Carmelo Bolívar, César Ovalles, Juan José García, and Youssef Espidel. Reversible adsorption of carbon dioxide on amine surface-bonded silica gel. Inorganica Chimica Acta, 240(1):183-189, 1995.

[27] Hailian Li, Mohamed Eddaoudi, Michael O'Keeffe, and Omar M Yaghi. Design and synthesis of an exceptionally stable and highly porous metal-organic framework. Nature, 402(6759):276-279, 1999.

[28] Jian-Rong Li, Ryan J Kuppler, and Hong-Cai Zhou. Selective gas adsorption and separation in metal-organic frameworks. Chemical Society Reviews, 38(5):1477-1504, 2009.

[29] Zhijian Liang, Bandar Fadhel, Caspar J Schneider, and Alan L Chaffee. Stepwise growth of melamine-based dendrimers into mesopores and their co 2 adsorption properties. Microporous and Mesoporous Materials, 111(1):536-543, 2008.

[30] Xiuwu Liu, Jingwen Li, Li Zhou, Desheng Huang, and Yaping Zhou. Adsorption of co 2, ch 4 and n 2 on ordered mesoporous silica molecular sieve. Chemical physics letters, 415(4):198-201, 2005. 
[31] Xiaoliang Ma, Xiaoxing Wang, and Chunshan Song. "molecular basket" sorbents for separation of $\mathrm{co} 2$ and h2s from various gas streams. Journal of the American Chemical Society, 131(16):5777-5783, 2009.

[32] David S. Mebane, K. Sham Bhat, Joel D. Kress, Daniel J. Fauth, McMahan L. Gray, Andrew Lee, and David C. Miller. Bayesian calibration of thermodynamic models for the uptake of co2 in supported amine sorbents using ab initio priors. Phys. Chem. Chem. Phys., 15:4355-4366, 2013.

[33] David S Mebane, Daniel J Fauth, and ML Gray. A rigorous yet scalable kinetic model for the uptake of co2 by silica-supported, pei-impregnated sorbents. Twenty-Eighth Annual International Pittsburgh Coal Conference, 2011.

[34] David S Mebane, Joel D Kress, Curtis B Storlie, Daniel J Fauth, McMahan L Gray, and Kuijun Li. Transport, zwitterions, and the role of water for co2 adsorption in mesoporous silica-supported amine sorbents. The Journal of Physical Chemistry C, 117(50):26617-26627, 2013.

[35] Bert Metz, Ogunlade Davidson, Heleen De Coninck, Manuela Loos, Leo Meyer, et al. Carbon dioxide capture and storage. 2005.

[36] David C. Miller, Madhava Syamlal, David S. Mebane, Curt Storlie, Debangsu Bhattacharyya, Nikolaos V. Sahinidis, Deb Agarwal, Charles Tong, Stephen E. Zitney, Avik Sarkar, Xin Sun, Sankaran Sundaresan, Emily Ryan, Dave Engel, and Crystal Dale. Carbon capture simulation initiative: A case study in multiscale modeling and new challenges. Annual Review of Chemical and Biomolecular Engineering, 5(1):301-323, 2014.

[37] Andrew R Millward and Omar M Yaghi. Metal-organic frameworks with exceptionally high capacity for storage of carbon dioxide at room temperature. Journal of the American Chemical Society, 127(51):17998-17999, 2005. 
[38] Monoj Kumar Mondal, Hemant Kumar Balsora, and Prachi Varshney. Progress and trends in co 2 capture/separation technologies: a review. Energy, 46(1):431-441, 2012.

[39] Nathan W Ockwig, Olaf Delgado-Friedrichs, Michael O'Keeffe, and Omar M Yaghi. Reticular chemistry: occurrence and taxonomy of nets and grammar for the design of frameworks. Accounts of chemical research, 38(3):176-182, 2005.

[40] United States Department of Commerce - National Oceanic and Atmospheric Administration. Trends in atmospheric carbon dioxide, 2016. 2016-03-24.

[41] R Sanz, G Calleja, A Arencibia, and ES Sanz-Perez. Co 2 adsorption on branched polyethyleneimine-impregnated mesoporous silica sba-15. Applied Surface Science, 256(17):5323-5328, 2010.

[42] Dushyant Shekhawat, David R Luebke, and Henry W Pennline. A review of carbon dioxide selective membranes. US department of energy, pages 9-11, 2003.

[43] Won-Jin Son, Jung-Sik Choi, and Wha-Seung Ahn. Adsorptive removal of carbon dioxide using polyethyleneimine-loaded mesoporous silica materials. Microporous and Mesoporous Materials, 113(1):31-40, 2008.

[44] Brett P Spigarelli and S Komar Kawatra. Opportunities and challenges in carbon dioxide capture. Journal of CO2 Utilization, 1:69-87, 2013.

[45] S Alexander Stern. Polymers for gas separations: the next decade. Journal of Membrane Science, 94(1):1-65, 1994.

[46] Tetsuo Tsuda, Tsuyoshi Fujiwara, Yasushi Taketani, and Takeo Saegusa. Amino silica gels acting as a carbon dioxide absorbent. Chemistry Letters, (11):2161-2164, 1992.

[47] MJ Tuinier, M van Sint Annaland, Gert Jan Kramer, and JAM Kuipers. Cryogenic co2 capture using dynamically operated packed beds. Chemical Engineering Science, 65(1):114-119, 2010. 
[48] Bo Wang, Adrien P Côté, Hiroyasu Furukawa, Michael O'Keeffe, and Omar M Yaghi. Colossal cages in zeolitic imidazolate frameworks as selective carbon dioxide reservoirs. Nature, 453(7192):207-211, 2008.

[49] Xiaochun Xu, Chunshan Song, John M Andresen, Bruce G Miller, and Alan W Scaroni. Novel polyethylenimine-modified mesoporous molecular sieve of mcm-41 type as highcapacity adsorbent for co2 capture. Energy \& Fuels, 16(6):1463-1469, 2002.

[50] Omar M Yaghi, Michael O'Keeffe, Nathan W Ockwig, Hee K Chae, Mohamed Eddaoudi, and Jaheon Kim. Reticular synthesis and the design of new materials. Nature, 423(6941):705-714, 2003.

[51] Cheng-Hsiu Yu, Chih-Hung Huang, and Chung-Sung Tan. A review of co2 capture by absorption and adsorption. Aerosol Air Qual. Res, 12(5):745-769, 2012.

[52] Ming B Yue, Yuan Chun, Yi Cao, Xin Dong, and Jian H Zhu. Co2 capture by asprepared sba-15 with an occluded organic template. Advanced Functional Materials, 16(13):1717-1722, 2006.

[53] V Zelenak, Da Halamova, L Gaberova, E Bloch, and P Llewellyn. Amine-modified sba12 mesoporous silica for carbon dioxide capture: Effect of amine basicity on sorption properties. Microporous and Mesoporous Materials, 116(1):358-364, 2008. 